Revue des patrimoines

\title{
Les églises paroissiales construites dans la seconde moitié du XX siècle et leur devenir : l'exemple de Lyon (Rhône)
}

\section{Maryannick Chalabi}

\section{OpenEdition}

\section{Journals}

Édition électronique

URL : http://journals.openedition.org/insitu/5887

DOI : 10.4000/insitu.5887

ISSN : 1630-7305

Éditeur

Ministère de la culture

Référence électronique

Maryannick Chalabi, «Les églises paroissiales construites dans la seconde moitié du XXe siècle et leur devenir : l'exemple de Lyon (Rhône) », In Situ [En ligne], 11 | 2009, mis en ligne le 05 juin 2013, consulté le 01 mai 2019. URL : http://journals.openedition.org/insitu/5887 ; DOI : 10.4000/insitu.5887

Ce document a été généré automatiquement le 1 mai 2019.

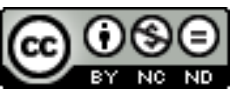

In Situ Revues des patrimoines est mis à disposition selon les termes de la licence Creative Commons Attribution - Pas d'Utilisation Commerciale - Pas de Modification 4.0 International. 


\title{
Les églises paroissiales construites dans la seconde moitié du XX $X^{e}$ siècle et leur devenir : l'exemple de Lyon (Rhône)
}

\author{
Maryannick Chalabi
}

1 Au XX ${ }^{e}$ siècle, le paysage du diocèse de Lyon $^{1}$, comme celui de la plupart des diocèses de France, en particulier des diocèses urbains, s'est profondément modifié. Plusieurs phénomènes interfèrent sur ces changements. L'exode rural entraîne un afflux de population dans les villes, en particulier dans les banlieues, ce qui nécessite la création de paroisses et l'ouverture de nouveaux lieux de culte ; ces constructions, engagées dans les années 1920-1930, se multiplient dans la période 1960-1970. Dans le même temps, l'Église s'interroge sur sa place dans la cité ainsi que sur l'exercice et le rôle de la pastorale, interrogations qui reçoivent un certain nombre de réponses dans les préconisations du concile Vatican II et la réforme liturgique qui s'ensuit ; cette réforme a évidemment des répercussions sur la disposition et l'aménagement des églises. Enfin, ecclésiastiques et artistes n'ont cessé de réfléchir sur la place de l'art du $\mathrm{XX}^{\mathrm{e}}$ siècle dans l'architecture religieuse et sur la spécificité de l'art sacré, réflexions qui se sont exprimées au cours du siècle à travers de véritables plaidoyers pour ou contre l'art moderne.

\section{Croissance démographique et urbanisme dans l'agglomération lyonnaise}

2 La transformation de l'agglomération lyonnaise au cours de la deuxième moitié du XX siècle est considérable: entre 1954 et 1999, l'aire urbaine de Lyon a gagné 700000 habitants, passant de 930000 à 1,6 millions d'habitants, avec un pic pour la période 1954-1968. En 1959, d'après le plan d'aménagement du territoire, on estime à 148000 le nombre de logements à construire, tant pour rebâtir un parc notablement insalubre que pour répondre à l'accroissement démographique. Le taux d'occupation du sol passe de 
600 habitants à l'hectare en 1945, à 1500 voire 2000 dans certaines zones en $1957^{2}$. Reconstructions in situ et lotissements de nouveaux espaces vont se réaliser en parallèle.

En 1959, Mgr Dupuy, archevêque de Lyon, présente ainsi l'évolution de son diocèse ${ }^{3}$ : la population du diocèse a augmenté de 400000 habitants en 50 ans (auxquels il faut ajouter les 135000 habitants des cantons villeurbannais autrefois du diocèse de Grenoble et qui viennent d'être rattachés en 1955 à celui de Lyon ${ }^{4}$ ) ; le pourcentage entre les populations rurale et urbaine a été inversé, la population urbaine représentant désormais $62 \%$ de la population totale du diocèse. Cet accroissement se faisait déjà sentir pendant la première moitié du siècle et la création des nouvelles paroisses avait été prise en charge par un organisme "Le Christ dans la banlieue»; 17 paroisses avaient alors été créées dans l'agglomération lyonnaise. Mais depuis la guerre, les conditions de l'urbanisation obéissent à des règles nouvelles : les constructions, de plus en plus rapides ${ }^{5}$, sont réalisées par de grands organismes et répondent à des réglementations sévères. Le diocèse doit répondre à cette évolution et créer de véritables agences d'urbanisme.

\section{L'Office diocésain des paroisses nouvelles}

L'Euvre du Christ dans la banlieue était plutôt un organisme de mission à destination du monde ouvrier. Pour répondre à des besoins plus vastes, le diocèse se dote d'une commission d'art sacré dès 1956 et l'année suivante, en octobre 1957, de l'Office diocésain des paroisses nouvelles (O.D.P.N.). Présidé par Mgr Dupuy, puis par Mgr Mazioux, sa mission est « d'organiser et de conduire au mieux l'opération églises nouvelles sur l'ensemble du diocèse $"^{6}$. Mais c'est l'évêque en dernier ressort qui décide de l'érection de nouvelles paroisses ainsi que du choix des programmes et des projets.

5 L'O.D.P.N. comprend six sections, réorganisées et complétées en 1960-1961:

- une section d'études sociologiques, l'Institut de sociologie religieuse des facultés catholiques ;

- une section financière, complétée d'une commission des prêts d'urgence ;

- une section juridique, chargée de l'achat des terrains et des relations avec les organismes publics, ainsi que de l'aide à apporter aux associations diocésaines ;

- une section technique, et une commission des programmes ;

- une section de propagande constituée par les membres de l'ÆEuvre du Christ dans la banlieue, puis une commission de l'information ;

- une section pastorale.

6 C'est à l'O.D.P.N. de dresser la liste des quartiers où les nécessités pastorales imposent la création de nouveaux lieux de culte. Il le fait soit directement par sa connaissance de l'évolution urbaine, soit en examinant les demandes de paroissiens ou de prêtres. En 1964, l'office signale que 18 projets qui ne correspondaient pas à de réelles nécessités pastorales ont été refusés ${ }^{7}$. Dans les nouvelles cités créées par le plan d'aménagement urbain (unités de voisinage, puis ZUP), les emplacements de lieux de culte sont réservés ; dans les cas de restructuration de quartiers, le diocèse, et pratiquement le futur desservant, doit trouver les terrains. L'Office insiste sur ce choix : "Son emplacement est très important. Il est commandé par des facteurs sociologiques, psychologiques, techniques. On ne peut éloigner la maison de Dieu de l'école, du bureau de bienfaisance, des locaux paroissiaux, de la cure. Le lieu de culte doit être autant que possible le centre du quartier. Éviter les phénomènes psychologiques écartant les fidèles de l'église : traversée de voies ferrées, déclivité à monter, pont, 
etc... Éviter la proximité d'une rue trop fréquentée... » ${ }^{8}$. En général, l'O.D.P.N. finance l'achat des terrains et l'Association diocésaine en devient propriétaire.

Lors des constructions, la direction des travaux est laissée aux initiatives locales ; il n'y a pas de centralisation. Pour chaque nouveau centre paroissial, ou futur centre paroissial, un comité de patronage comprenant le desservant et des laïcs est mis sur pied pour évaluer l'ampleur des constructions à réaliser, choisir l'architecte et les entrepreneurs, décider des plans après avis de la section technique et de la commission d'art sacré; l'office insiste en particulier sur la nécessité d'une enquête sociologique précise permettant d'évaluer l'importance du quartier, le nombre d'habitants, et d'enfants, attendus. Une fois le projet arrêté, ce comité est remplacé par l'association paroissiale, dûment mandatée par l'association diocésaine, propriétaire des terrains et des futurs locaux, pour mener à bien la réalisation. Simple mandataire de l'association diocésaine, l'association paroissiale ne peut traiter qu'après l'accord de celle-ci; le permis de construire en particulier est demandé au nom de l'association diocésaine.

Certaines acquisitions peuvent conduire à des imbroglios juridiques. Par exemple, pour la création de la paroisse du Christ-Roi à Bron-Parilly, l'Office d'HLM était prêt, en 1956, à céder un terrain au diocèse, ce qui lui est interdit par la loi de Séparation de l'Église et de l'État; pour contourner cette interdiction, en 1960, il concède la parcelle à l'association diocésaine par un bail emphytéotique de 99 ans passé sous seing privé ; cet acte n'a pu être enregistré faute de document d'arpentage ; lorsque ce document est enfin rédigé en 1963, Mgr Dupuy, qui avait signé le premier acte au nom de l'association, n'est plus en charge à Lyon et un nouveau bail doit alors être établi ${ }^{9}$.

9 Dans d'autres cas, les choses semblent moins claires. Ainsi, pour Sainte-Marie de la Guillotière ${ }^{10}$ créée sur l'insistance de l'abbé de Pazanan, un accord verbal avait été conclu, en 1952, entre le curé et le vicaire général par lequel l'archevêché s'engageait à payer les terrains trouvés par le curé qui se chargeait quant à lui, entièrement, de la construction de l'église. Or, au moment de l'achat du terrain en 1955, une partie, un million de francs, est payée par l'association diocésaine, et le reste, 2750000 francs, est seulement avancé par l'association pour un an, sans intérêt; finalement l'abbé de Pazanan obtint une réduction de 250000 francs en avançant son remboursement d'un trimestre.

L'accord passé, le 11 février 1961, entre l'association diocésaine et l'association paroissiale de Sainte-Bernadette (Caluire) est tout à fait précis : "L'archevêché de Lyon ayant décidé de créer un nouveau lieu de culte... a confié à l'association diocésaine le soin d'acquérir le terrain... et de procéder à la construction et à l'aménagement de ces édifices. L'association diocésaine ne disposant ni des moyens, ni des ressources nécessaires pour l'exécution de cette mission, se trouve dans l'obligation pour la mener à bonne fin, de faire appel au concours des habitants du quartier... L'association paroissiale étant... simple mandataire de l'association diocésaine, les constructions élevées sur ce terrain... deviendront la propriété de l'association diocésaine... ».

11 Mais le plus souvent, l'association paroissiale doit trouver les financements pour rembourser les sommes avancées par le diocèse. Plusieurs solutions lui sont proposées : des ressources propres provenant des paroissiens, d'éventuels dons et legs faits à l'association, et enfin la solidarité de l'ensemble du diocèse : chaque paroisse est appelée à prendre en charge une paroisse nouvelle, à en être "marraine ", à lui porter assistance ; le curé fondateur doit s'y rendre au moins une fois par an pour rendre compte de l'évolution des travaux et de l'utilisation des sommes collectées. 
12 Selon la personnalité des curés bâtisseurs, les recherches de financement sont très variées. En plus des ressources classiques citées ci-dessus, des kermesses et fêtes diverses, d'autres solutions peuvent être trouvées. Certains peuvent jouer de leurs relations ; ainsi l'abbé de Pazanan aurait eu appui et subsides du Saint-Siège, en plus de ses ressources propres acquises au Brésil, pour la construction de Sainte-Marie de la Guillotière. D'autres se transforment en chiffonnier comme le curé de la Sainte-Trinitée ${ }^{11}$.

13 Très souvent, les constructions d'églises sont de véritables épreuves pour le desservant et l'association paroissiale. On peut lire dans un compte rendu de réunion de l'O.D.P.N. d'avril 1979 concernant l'église Saint-François d'Assise (Saint-Rambert, 9e arrondissement) : « le père F. est très impressionné - à la suite de ses déboires précédents à Irigny - par l'idée d'une construction nouvelle». Son inquiétude était justifiée. Pourtant l'association paroissiale, qui par ailleurs, de façon exceptionnelle, a refusé toute responsabilité financière dans le projet, agit avec prudence: elle choisit comme architecte M. Tolot: "il a si bien réussi l'église de la Sauvegarde et a accepté de modifier ses plans plus de dix fois ». Le choix était judicieux: en janvier 1980, le procès-verbal de la réunion de l'Office annonce «M. Tolot, architecte, avec une patience exemplaire, a remis plusieurs fois ses projets à jour pour tenir compte des modifications demandées et des suggestions faites. Finalement, le dernier projet qui porte le $n^{\circ} 5$ paraît donner complètement satisfaction... ». Mais, en septembre, la SERL (Société d'Économie mixte de la Région lyonnaise, promoteur de l'opération d'urbanisme) demande une modification du projet, suite à une intervention d'élus du quartier qui trouvaient que l'installation du presbytère sur deux niveaux s'intégrait mal dans l'ensemble des bâtiments. L'architecte accepte une fois encore de modifier ses plans, et l'église est finalement achevée en février $1983^{12}$.

14 Le nombre des chantiers à entreprendre augmente d'année en année : estimé à 85 centres à créer en 1959, le nombre passe à 120 en 1964. Pour financer les achats de terrains, l'association diocésaine décide de contracter un emprunt en décembre 1956, emprunt de 100 millions de francs, réalisé par obligations de $10000 \mathrm{~F}$. à $5 \%$ d'intérêts et remboursables en 15 ans. Pour ce remboursement, le diocèse augmente les honoraires des messes de 300 à $350 \mathrm{~F}$. et obtient, par autorisation expresse du Saint-Siège, que ces $50 \mathrm{~F}$ supplémentaires soient versés à l'Association diocésaine ${ }^{13}$.

15 Un second emprunt de 200 millions de francs est lancé en avril 1959, selon le même principe $^{14}$. À sa clôture, le 15 juillet, il manque encore 20 millions ${ }^{15}$.

À partir de 1960, l'association diocésaine obtient l'autorisation de contracter des emprunts auprès de la Caisse des dépôts, garantis par les conseils généraux du Rhône et de la Loire.

L'O.D.P.N. peut aider certains projets par des prêts sans intérêt pendant 5 ans. Les fonds proviennent de la quête du Christ-Roi (en augmentation), de dons faits directement à la caisse centrale, et d'une centaine de millions d'anciens francs prêtés sans intérêt par des particuliers pendant 5 ans, mais dont le remboursement doit se faire avant 1967.

Les appels aux paroisses et à la générosité des fidèles se font plus pressants. En octobre 1960, l'évêque demande qu'un comité chargé d'enregistrer les engagements et les versements pour les églises nouvelles soit créé dans chaque paroisse ${ }^{16}$. Le 14 avril 1961, il donne une directive aux archiprêtres: le diocèse doit pouvoir financer les 80 églises, à construire ou en construction, par le système du parrainage et par la recherche d'emprunts auprès des particuliers, dont le remboursement sera garanti par l'association diocésaine ${ }^{17}$. 
19 Dans son rapport présenté à la réunion générale de l'O.D.P.N. du 19 juin 1963, le président, Mgr Mazioux, insiste sur le rôle des paroisses marraines et des comités laïcs porteurs de projets ${ }^{18}$ : il faudrait que les paroisses donnent chaque année l'équivalent du denier du culte. À cette date, elles ont versé en moyenne 58,32\% au premier exercice et $54,94 \%$ au second. Mgr Mazioux demande d'établir le principe de deux quêtes par an pour les églises nouvelles : une quête destinée au curé bâtisseur, et l'autre versée directement à l'O.D.P.N. ${ }^{19}$

20 Cependant au fil des années, les paroisses répondent de moins en moins aux appels diocésains.

21 En septembre 1964, la situation financière se présente ainsi ${ }^{20}$ :

22 Évolution des ressources venant des paroisses qui bâtissent, des marraines et de la caisse centrale

\begin{tabular}{|l|l|}
\hline $1960-61$ & $2230530,49 \mathrm{~F}$ \\
\hline $1961-62$ & $2785367,31 \mathrm{~F}$ \\
\hline $1962-63$ & $1943615,70 \mathrm{~F}$ \\
\hline
\end{tabular}

Moyennes des versements des paroisses marraines par rapport aux versements du denier du culte, provenant de la quête du Christ-Roi, de la quête des prêtres bâtisseurs et des souscriptions annuelles.

\begin{tabular}{|l|l|}
\hline $1960-61$ & $60,57 \%$ \\
\hline $1961-62$ & $57,94 \%$ \\
\hline $1962-63$ & $43,87 \%$ \\
\hline
\end{tabular}

Les paroisses qui bâtissent versent en moyenne de trois à cinq fois l'équivalent du denier du culte.

\begin{tabular}{|l|l|l|}
\hline Années & Nombre de paroisses & \\
\hline & $\begin{array}{l}\text { Ayant versé moins de } 40 \% \text { du denier du } \\
\text { culte }\end{array}$ & $\begin{array}{l}\text { Ayant versé moins de } 20 \% \text { du denier du } \\
\text { culte }\end{array}$ \\
\hline $1960-61$ & 414 & 276 \\
\hline $1961-62$ & 418 & 297 \\
\hline $1962-63$ & 440 & 355 \\
\hline
\end{tabular}




\section{L'anpleur de la tâche et la durée des efforts demandés découragent les paroisses} marraines. Dans son appel d'octobre 1966 pour la quête en faveur des paroisses nouvelles, l'archevêque précise : «Est-il besoin de rappeler que l'office diocésain a écarté plusieurs projets de centres religieux qui ne semblaient pas rigoureusement indispensables? Et que les églises ou chapelles à construire auront de plus en plus un caractère de simplicité qui s'harmonise avec notre souci missionnaire? $»^{21}$. Il rappelle aussi à plusieurs reprises la nécessité pour les curés bâtisseurs d'aller rendre compte de leur projet et de son avancement auprès des paroisses marraines, ce que beaucoup ne font pas. Les contestations vont parfois plus loin. Des fidèles de Saint-Martin d'Ainay, paroisse marraine de l'église Sainte-Trinité22, s'inquiètent dans une lettre à l'évêque : «Depuis 11 ans Ainay envoie $20000 \mathrm{~F}$ à chaque année à la SainteTrinité, sa filleule, après avoir donné beaucoup plus les premières années. Allez maintenant à la cure de la Ste Trinité, vous y trouverez un confort et un luxe que nous ne nous permettons pas à Ainay. Quant à l'église, dans laquelle faut-il faire le plus de frais (en raison des réparations nécessaires)... Combien de temps encore faudra-t-il qu'Ainay verse à la Sainte-Trinité... un argent dont elle est persuadée qu'il devrait être dépensé autrement... $»^{23}$.

En octobre 1968, sur les 120 projets annoncés sur l'ensemble du diocèse, 70 ont été réalisés pour un coût de $26358000 \mathrm{~F}$, sur lesquels il reste 6 millions de francs d'emprunts à rembourser, six chantiers sont en cours et quatorze prévus d'ici la fin de 1969. Pour Lyon et sa proche banlieue, ce sont 40 églises, centres paroissiaux ou chapelles annexes qui ont été construits entre 1951 et 1983.

\section{Comment construire}

La région Rhône-Alpes a été le lieu d'un profond débat sur l'art sacré avec la décoration intérieure de l'église du plateau d'Assy ${ }^{24}$ (Haute-Savoie), consacrée en 1950, en particulier autour du Christ de Germaine Richer que l'évêque d'Annecy dut faire retirer de l'église ${ }^{25}$. En 1959, l'architecture moderne est reconnue dans la région avec la construction du couvent des dominicains de la Tourette à Éveux ${ }^{26}$ (Rhône) par Le Corbusier.

Pourtant les prescriptions du diocèse en matière de construction et d'aménagement des églises restent classiques. En 1956, la Semaine religieuse rappelle l'instruction du SaintOffice sur l'art sacré du 30 juin 1952 : «...Personne n'ignore les aberrations qui, en matière d'art sacré, ont trouvé une hospitalité complaisante dans les expositions privées et publiques et qui ... ont eu malheureusement accès, en quelque cas, jusque dans les églises...... Les organismes diocésains ou nationaux... voudront bien veiller à ce que la charge des travaux d'art sacré ne soit pas confiée à des artistes qui, par manque de foi ou de bonne volonté dans l'obéissance aux directives de l'Église, ne donnent pas de garanties suffisantes en ce domaine... $"{ }^{27}$.

La commission d'art sacré du diocèse doit être obligatoirement consultée pour tout achat ou installation d'œuvres d'art. La section technique de l'O.D.P.N. étudie les plans de construction dressés par les architectes dont le choix est laissé aux comités locaux; elle donne son avis sur les matériaux employés et les devis proposés; elle veille à la conformité des projets avec les prescriptions épiscopales : «...Pas de recherche, pas de luxe. N'oubliez pas que beaucoup sont encore très mal logés. Nous voulons une église où sera le corps $d u$ Christ; mais n'oubliez pas qu'il y a les membres du Christ qui attendent encore un logement 
convenable... ${ }^{28}$. "Nous devons veiller à ce que aucune dépense somptuaire ou superflue ne soit engagée. Nous devons nous borner à faire des choses simples, solides, pratiques, définitives.... La pauvreté sera un signe: les églises qui coûtent cher ne sont pas forcément les plus belles. De même qu'on ne demande plus à un curé d'être un notable, on ne demande plus à l'église d'être un monument... 40 millions de catholiques en France ont à construire 1200 églises. Ce n'est pas une affaire d'argent, c'est l'œuvre d'une église vivante... $»^{29}$.

Le tableau des constructions réalisées pendant 25 ans montre la diversité des architectes concernés, qui dans leur très grande majorité ne construisent qu'une église, dans la zone urbaine étudiée. Seul Pierre Genton en réalise quatre. Dès sa formation, l'O.D.P.N. s'est assuré le concours de deux architectes, Paul Curtelin et Jean-Gabriel Mortamet, rejoints en 1960 par Joseph Bacconnier, René Gagès, Marc Bissuel et François-Régis Cottin ${ }^{30}$. Les relations entre ces architectes, membres de la commission technique de l'O.D.P.N., les religieux et la commission d'art sacré, n'ont pas toujours été simples. En 1962, il est décidé de faire des réunions communes. Le point de désaccord le plus important entre les architectes et l'Office porte sur le coût des projets, l'Office reprochant aux architectes de se désintéresser de l'affaire ou de ne pas vouloir se prononcer ${ }^{31}$.

Dans cette œuvre de construction et de création de paroisses, plusieurs tendances se font jour, se croisent, s'opposent, se succèdent. Au lendemain de la guerre, le diocèse suit les principes défendus par le père Winninger: une paroisse pour 5000 habitants $^{32}$. Par la suite, compte tenu du développement de la circulation automobile autant que de la baisse de fréquentation des lieux de culte, on s'oriente vers une paroisse pour dix à quinze mille habitants. Ainsi 15 centres religieux sur les 95 prévus ont été abandonnés, et des paroisses créées prématurément supprimées (Notre-Dame de Lourdes et Sans-Souci) ${ }^{33}$.

Figure 1

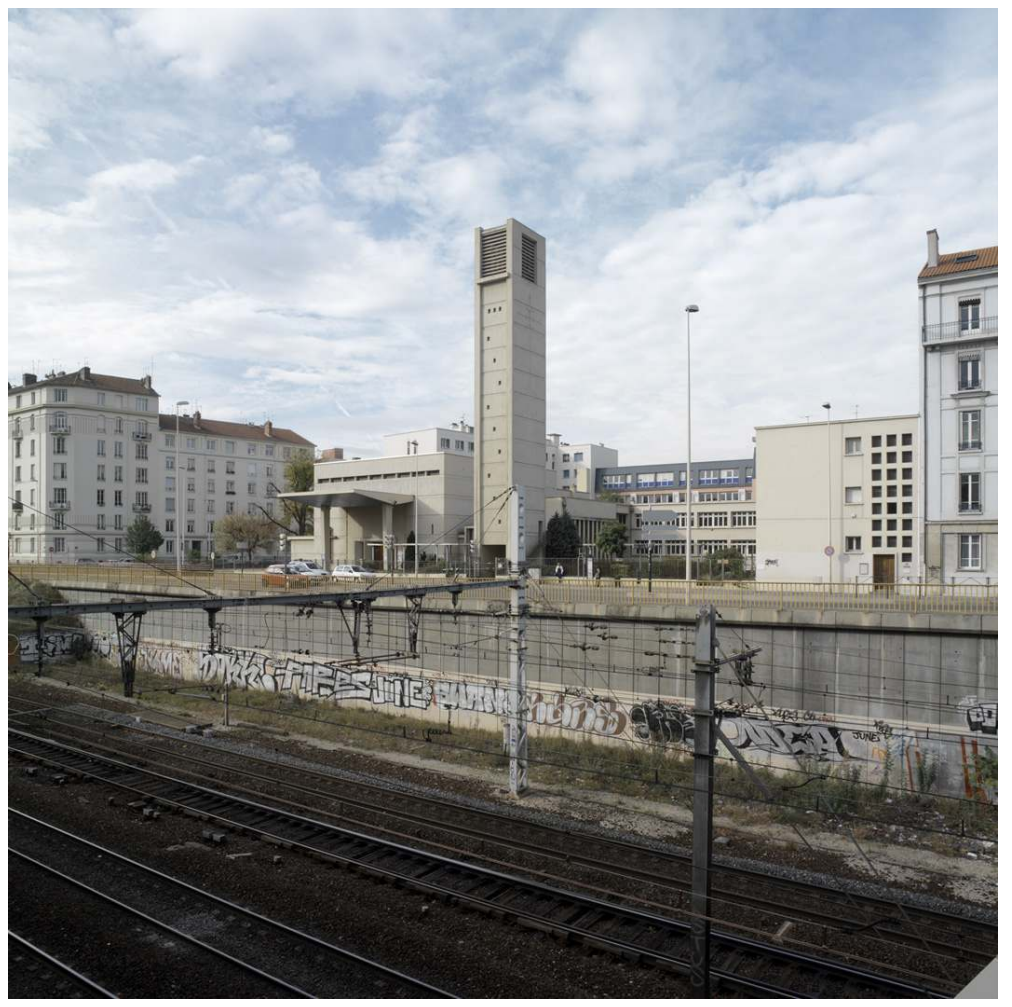

Vue d'ensemble de l'église Sainte-Marie de la Guillotière

Phot. É. Dessert, 2005. @ Région Rhône-Alpes, Inventaire général du patrimoine culturel 

construction de centres paroissiaux: à Sainte-Marie de la Guillotière ${ }^{34}$, l'église est accompagnée de logements pour le desservant, ses vicaires et les prêtres de passage ; plusieurs salles de réunions et de catéchisme sont disposées autour d'une vaste cour servant de parking (fig. $\mathbf{n}^{\mathbf{0}}$ 1). À Saint-Luc (Sainte-Foy-les-Lyon) ${ }^{35}$, Saint-Michel ${ }^{36}$ (7e arrondissement), la Sainte-Trinité ${ }^{37}$ (4e), l'église est construite à l'étage, le rez-dechaussée accueillant outre les salles de catéchisme et de réunions, de vastes espaces pouvant servir de salles de réception pour les fêtes ou même de véritables salles de spectacle comme à la Sainte Trinité.

En complément de ces centres, on construit des annexes comportant une chapelle et des salles de catéchisme. Dès 1967, la solution adoptée à La Duchère avec une seule paroisse, mais quatre églises pour une population prévue de 21000 habitants, est considérée comme une erreur et opposée au choix réalisé aux Minguettes (Vénissieux) : un centre paroissial pour une cité de 40000 habitants avec une seule annexe ${ }^{38}$. Dans cette cité, les desservants maintiennent le principe des prêtres ouvriers appliqué par le père Rémilleux, curé de Notre-Dame de Saint-Alban dès 1924 : un des prêtres est « prêtre au travail »; tous logent dans des appartements dispersés dans les HLM de la cité.

\section{Les constructions}

Figure 2

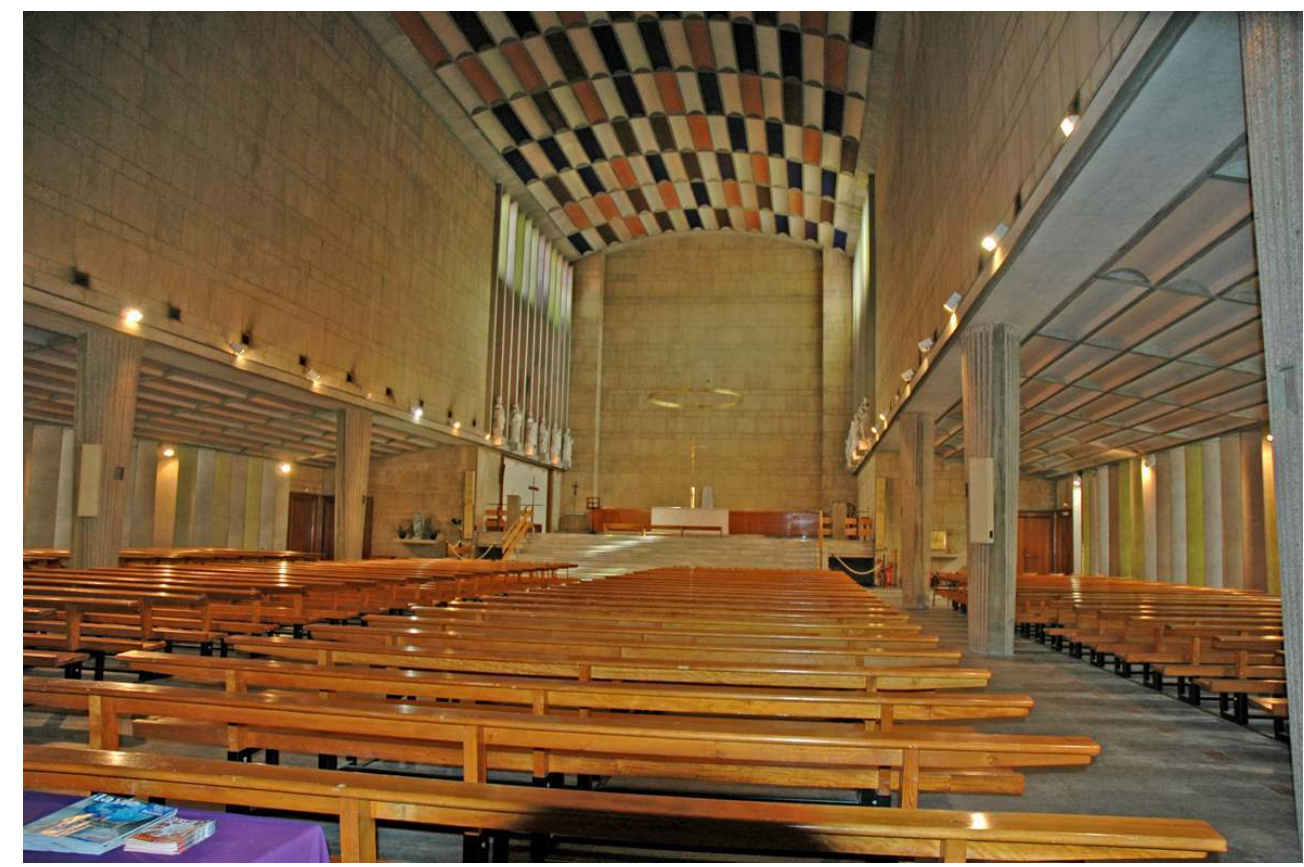

Église de l'Annonciation, Vaise. La nef

Phot. M. Chalabi, 2005. @ Région Rhône-Alpes, Inventaire général du patrimoine culturel

Les premiers travaux touchent les églises endommagées ou détruites par les bombardements. Deux sont restaurées ou rebâties à l'identique, Saint-Pierre de Vaise ${ }^{39}$ (9e arrondissement) et Saint-Vincent-de-Paul ${ }^{40}$ (8e arrondissement). L'église de l'Annonciation à Vaise ${ }^{4142}$ est reconstruite à partir de 1953 selon un projet ambitieux de 
Paul-Érasme Koch, architecte conseil pour la reconstruction des édifices cultuels en France. P.-E. Koch s'inscrit dans la doctrine de l'église-monument, qui doit marquer le quartier d'un signal, matérialisé ici par un clocher carré isolé de $62 \mathrm{~m}$ de haut prolongé par un couronnement de ferronnerie de $22 \mathrm{~m}$ qui accueille les quatre cloches et l'horloge ${ }^{43}$. Le parement de pierre rosée qui anime les murs extérieurs confirme le caractère monumental de l'édifice, prévu pour 900 fidèles. À l'intérieur, le plan basilical est modernisé par les colonnes cannelées plus minces à la base qui délimitent le bas-côté droit, et par le couvrement constitué de demi-cylindres en béton préfabriqué (fig. $n^{\circ} 2$ ).

Le percement du tunnel de la Croix-Rousse nécessite la démolition de l'église SaintCharles de Serin $^{44}$ qui est reconstruite légèrement plus au nord par l'architecte Louis Mortamet, en 1952. Située au centre d'une petite place faisant office de parking, sa façade ouvre fâcheusement sur la voie rapide débouchant du tunnel. L'église se distingue également par une tour-clocher carrée mais qui ne s'élève qu'à $31 \mathrm{~m}$. Les murs de béton sont simplement enduits de ciment (fig. $\mathrm{n}^{\circ} 3$ ). À l'intérieur, les travées de la nef rectangulaire sont ponctuées de grands arcs ajourés dont la retombée au sol est percée d'arcades formant une circulation simulant des bas-côtés (fig. $n^{\circ} 4$ ).

Figure 3

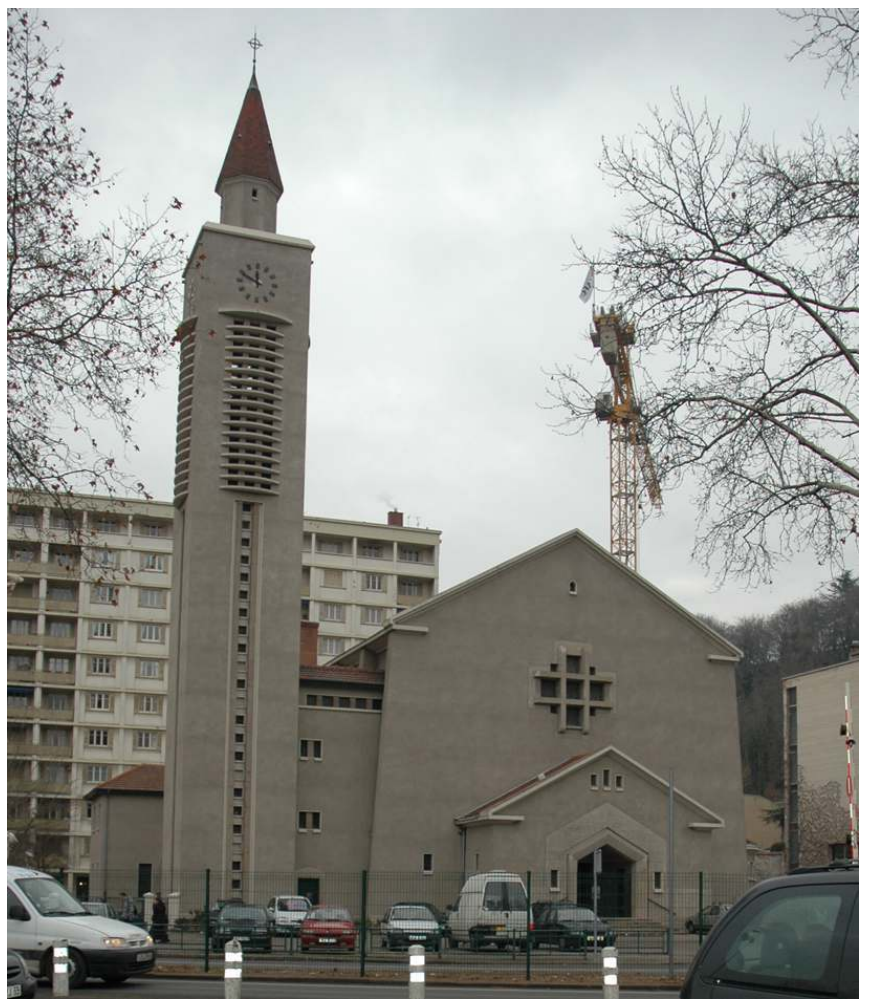

Église Saint-Charles de Serin. Façade principale

Phot. M. Chalabi, 2006. (c) Région Rhône-Alpes, Inventaire général du patrimoine culturel 
Figure 4

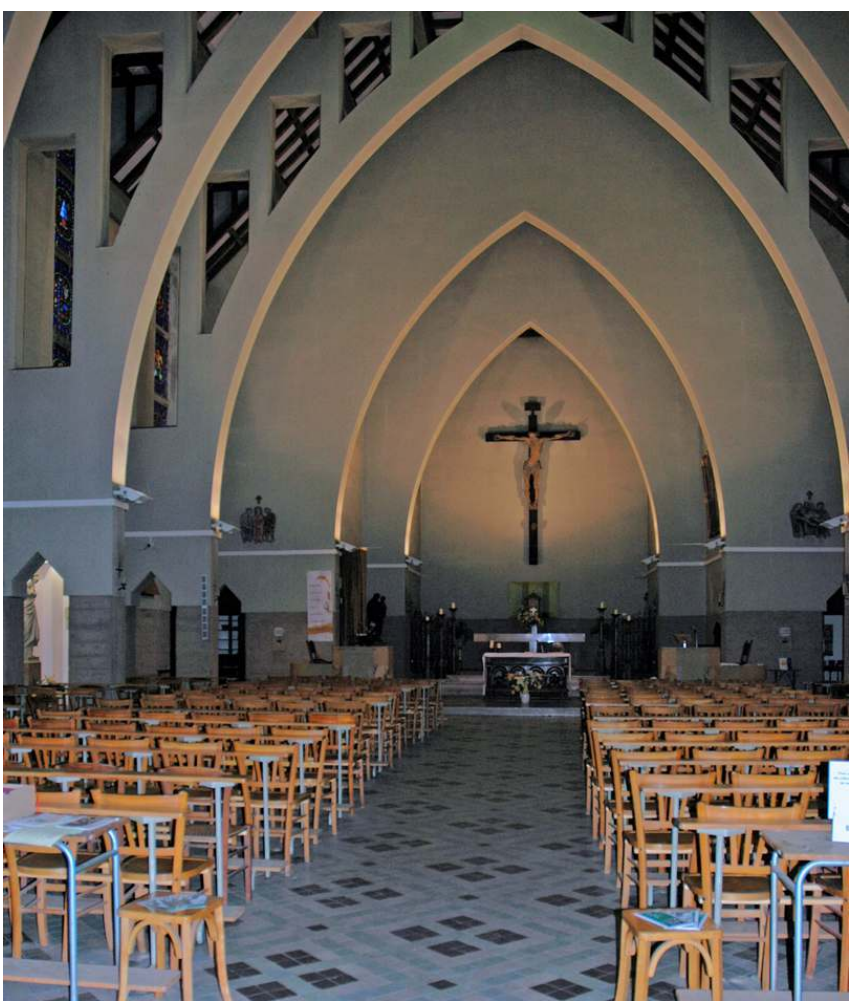

Église Saint-Charles de Serin. Les grandes arcades de la nef

Phot. M. Chalabi, 2006. @ Région Rhône-Alpes, Inventaire général du patrimoine culturel

Une tour-clocher carrée marque également l'église de la nouvelle paroisse Sainte-Marie de la Guillotière ${ }^{45}$, érigée à la limite des quartiers de la Guillotière et de Montplaisir. Son emplacement est également peu valorisant, en bordure du boulevard des Tchécoslovaques et de la voie ferrée; mais l'église, construite en 1959, bénéficie du voisinage d'un petit jardin de curé au nord, et d'une cour arborée au sud. L'abbé constructeur, très volontariste, aurait bénéficié d'appuis financiers du Saint-Siège, ce qui lui a permis de mener à bien un programme ambitieux avec une église de 600 places. L'architecte Joseph Bacconnier adopte un parti volontairement moderniste, à la fois dans l'emploi du béton brut de décoffrage, mais également dans l'aménagement intérieur: chevet plat recouvert de simples rideaux, chapelle de semaine et chapelle mortuaire fermées par des cloisons mobiles en accordéon (fig. $\mathbf{n}^{\circ} 5$ ). L'austérité de l'ensemble est adoucie par l'importance des vitraux de Paulin et Besson ${ }^{46}$ (voir ci-dessous). 
Figure 5

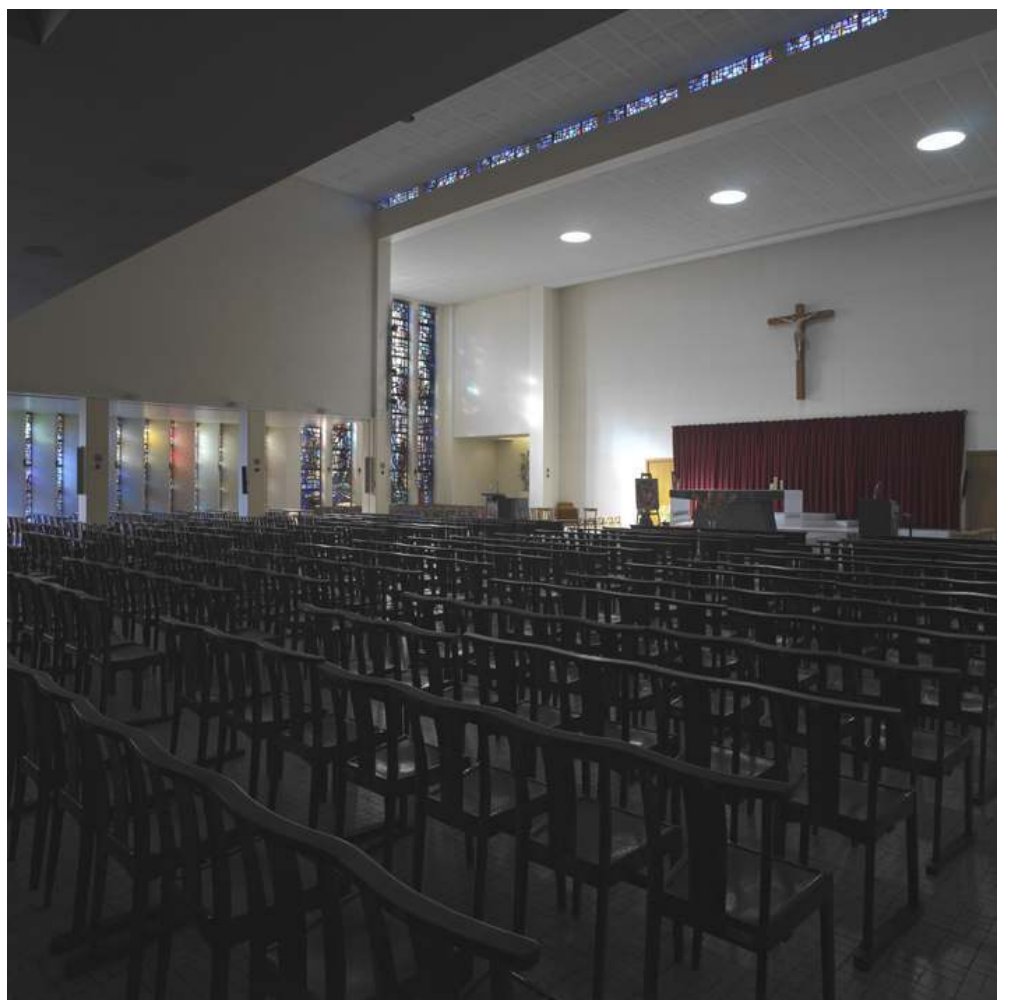

Église Sainte-Marie de la Guillotière. Vue d'ensemble de la nef

Phot. É. Dessert, 2006. @ Région Rhône-Alpes, Inventaire général du patrimoine culturel

Le manque de moyens autant que la volonté d'affirmer "la pauvreté de l'église dans un monde où règne l'argent ${ }^{47}$ poussent plusieurs curés à se détourner de l'église monument. C'est le cas des églises construites dans l'urgence, considérées comme des édifices provisoires devant répondre au service religieux, mais aussi offrir des lieux de rassemblement, de réunions pour les fidèles ou le reste de la population. Ces églises sont de vastes salles préfabriquées qui se distinguent peu des bâtiments environnants, telles deux églises de Bron, édifices provisoires devenus définitifs, le Christ-Roi, édifiée en 1957 pour l'unité de Bron-Parilly, par les architectes responsables du programme, Franck Grimal, René Gagès et Pierre Bourdeix, et Saint-François d'Assise, construite en 1959. 


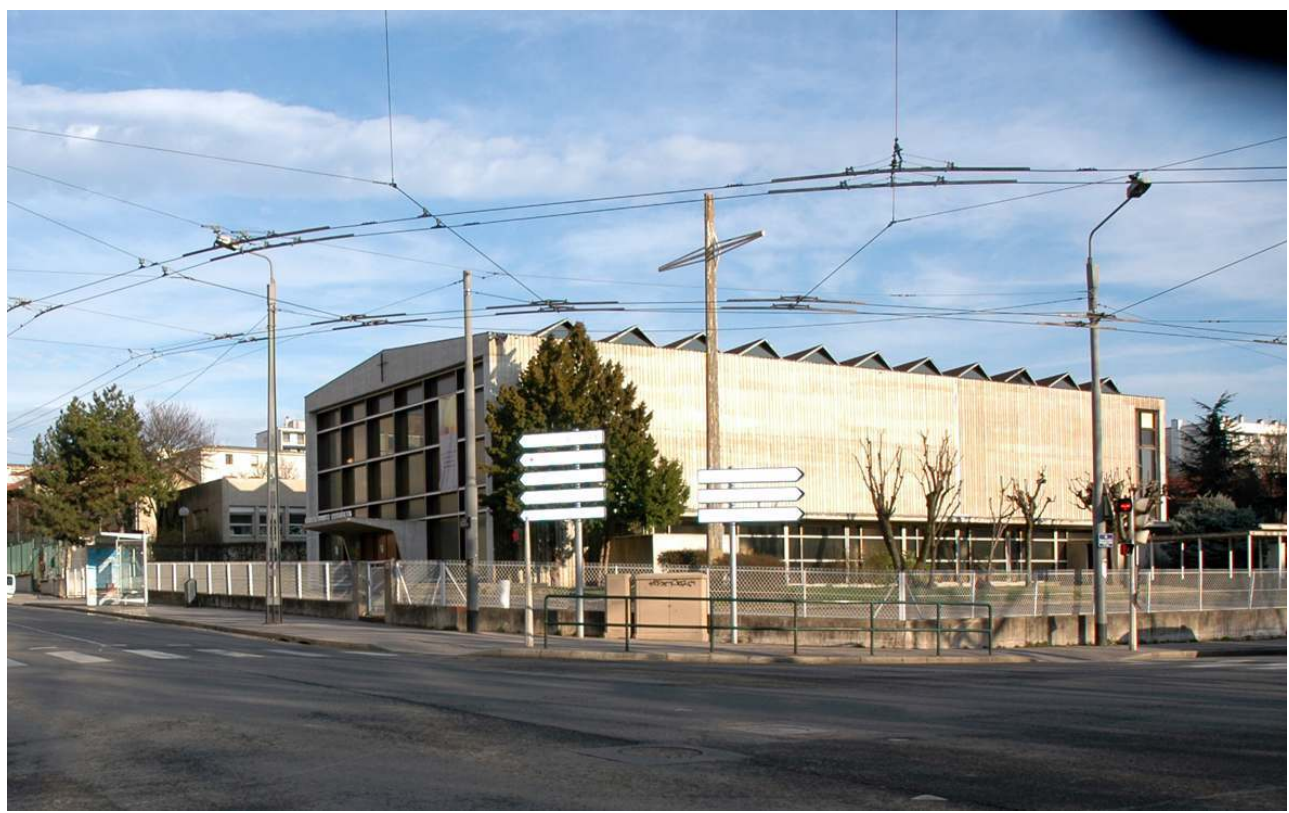

Église Sainte-Élisabeth. Vue d'ensemble

Phot. M. Chalabi, 2006. (C) Région Rhône-Alpes, Inventaire général du patrimoine culturel

39 L'église Sainte-Élisabeth ${ }^{48}$ (4e), construite par Daniel Genevois, Roger Mermet et Marcel Sabattier, se présente également comme un vaste édifice rectangulaire, dont le caractère sacré n'est marqué extérieurement que par une croix détachée, implantée sur le terrain du bâtiment, et dont la fonction est signalée par une inscription en façade "ÉGLISE SAINTE-ÉLISABETH » (fig. $\left.\mathbf{n}^{\circ} \mathbf{6}\right)$.

À partir de 1960, on assiste à un tournant à la fois dans le nombre des églises construites et dans les partis architecturaux adoptés. 24 églises ou centres paroissiaux sont construits dans la décennie à Lyon et ses communes adjacentes, dont 12 à Lyon même ; sept le sont après 1970 et ce uniquement dans les communes riveraines.

personnalité du curé-bâtisseur va jouer un rôle important, en particulier pour imposer un architecte choisi en fonction de relations privilégiées établies entre maître d'œuvre et maître d'ouvrage.

42 Ainsi, pour la construction de Saint-Jean Apôtre ${ }^{49}$ dans le quartier des États-Unis, le curé va imposer le projet d'Alain Chomel, encore étudiant en architecture travaillant dans le cabinet de son père, contre l'opinion de P.-E. Koch qui critiquait le manque de monumentalité de l'édifice. A. Chomel tire le meilleur parti de la parcelle triangulaire située en bout d'îlot (fig. $\mathbf{n}^{\circ} 7$ ) ; profondément influencé par Le Corbusier, il conçoit un édifice en béton brut particulièrement soigné, ponctué par une flèche de $24 \mathrm{~m}$ de haut, formant signal, et ouvert à la base sur un portique accueillant les fidèles (fig. $\mathbf{n}^{\circ} \mathbf{8}$ ). 
Figure 7

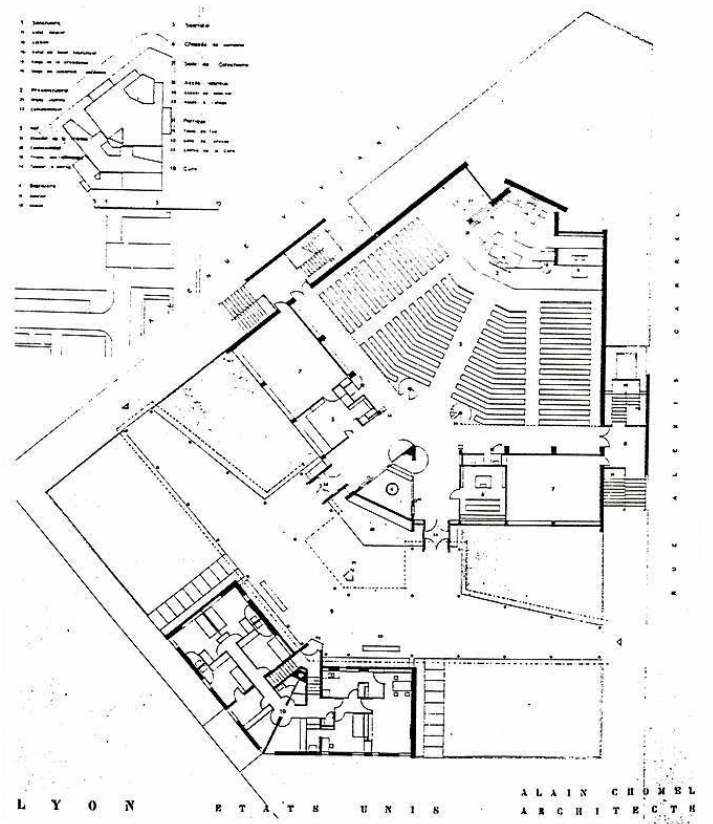

Plan du centre paroissial Saint-Jean-Apôtre / A. Chomel (A. diocésaines)

Phot. M. Chalabi, 2008. @ Région Rhône-Alpes, Inventaire général du patrimoine culturel 


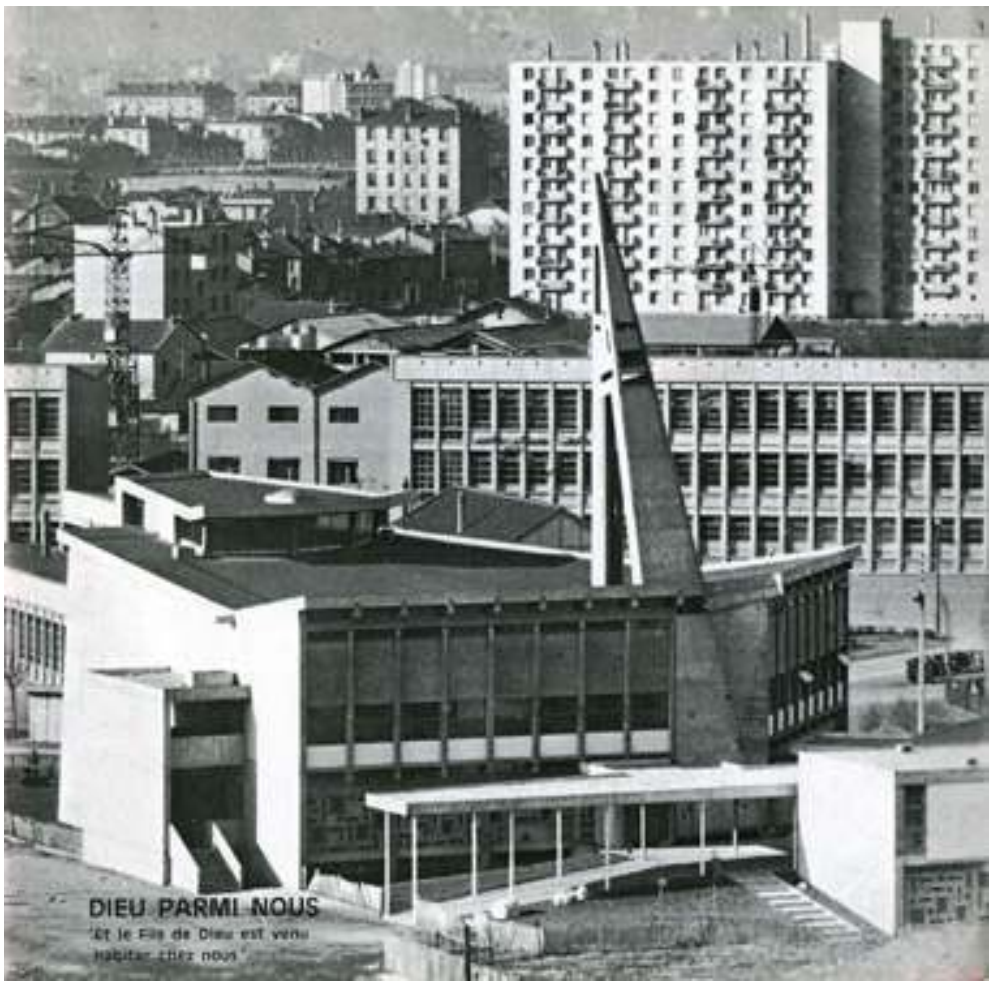

Église Saint-Jean-Apôtre. Vue d'ensemble, publiée dans une brochure paroissiale consacrée à l'église. Lyon : RAAG, 1964

Phot. M. Chalabi, 2008. @ Région Rhône-Alpes, Inventaire général du patrimoine culturel

Avec la Sainte-Trinité ${ }^{50}$, Pierre Genton va obtenir son premier chantier d'église à Lyon ${ }^{51}$. Ici encore, l'église ne s'impose pas comme monument ; édifiée en bordure d'une place, sa façade ne se distingue pas de celle d'un immeuble d'habitation (fig. $\mathbf{n}^{\circ}$ 9) ; l'entrée est marquée par un travail de ferronnerie soigné, imposant, mais non monumental : carillon et coq de Jacques Bouget ${ }^{52}$; il faut monter sur le parking des immeubles qui surplombent l'église à l'est pour voir l'ensemble de l'église et son lanterneau (fig. $\mathbf{n}^{\circ} \mathbf{1 0}$ ). Le caractère sacré de l'édifice reste discret, et se construit autour de la symbolique du carré évoquant la Jérusalem céleste, un carré de $36 \mathrm{~m}$ de côté, découpé en 12, suggérant les 12 portes de la ville sainte, les 12 tribus d'Israël et les 12 apôtres $^{53}$. 
Figure 9

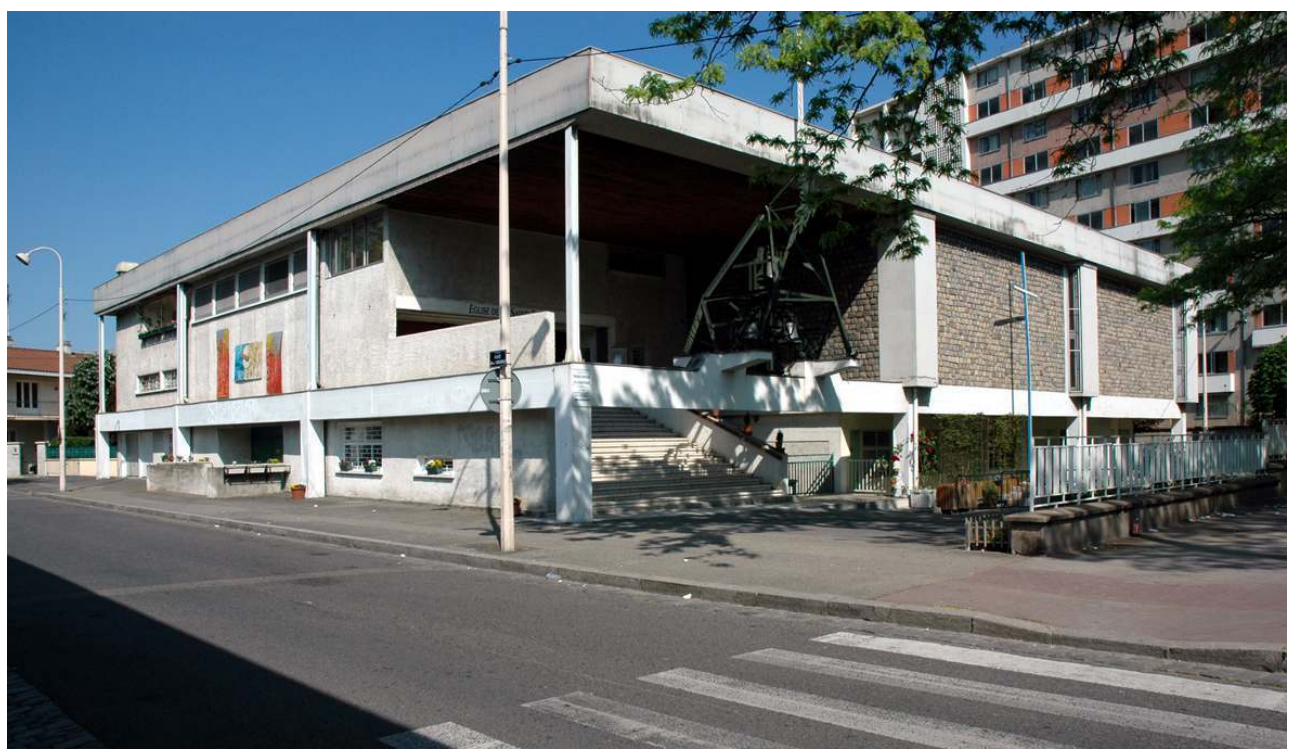

Église de la Sainte-Trinité. Vue d'ensemble sur la place

Phot. M. Chalabi, 2008. @ Région Rhône-Alpes, Inventaire général du patrimoine culturel.

Figure 10

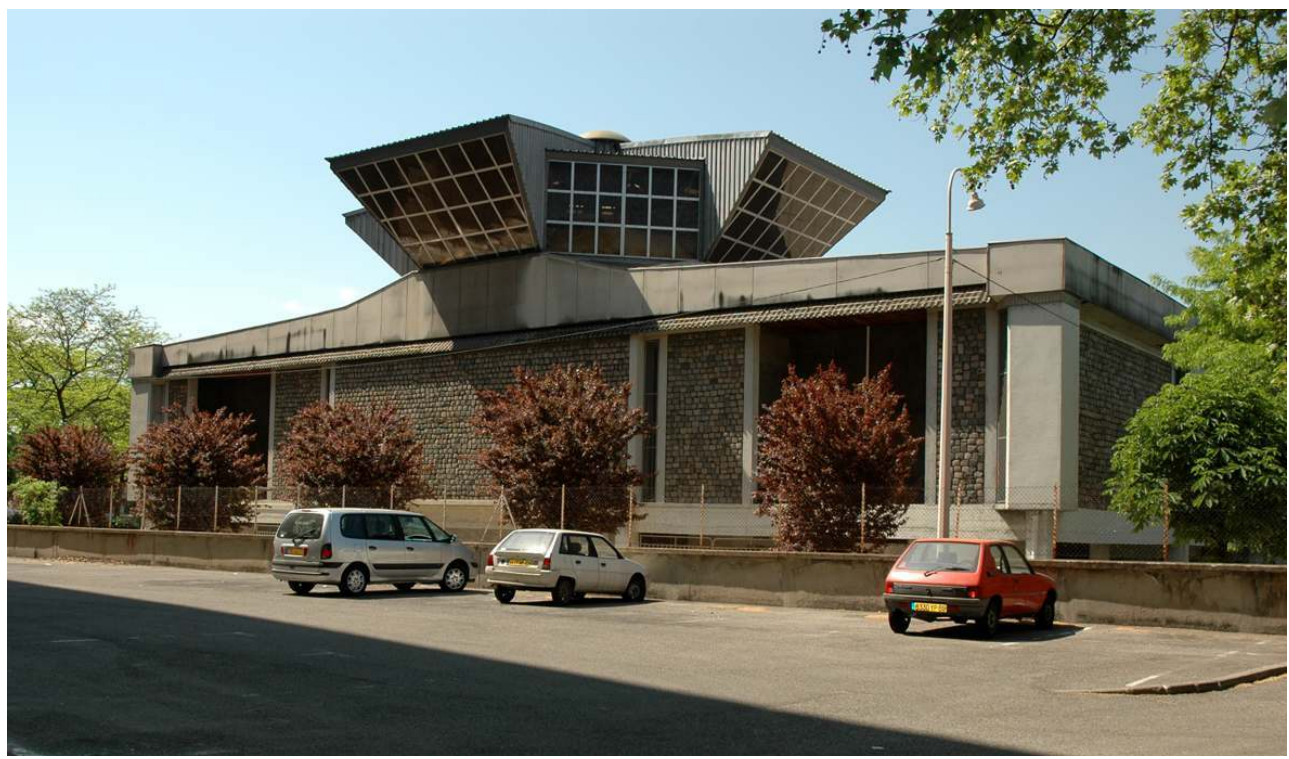

Église de la Sainte-Trinité. Le lanterneau vu depuis le parking surplombant l'église

Phot. M. Chalabi, 2008. (C) Région Rhône-Alpes, Inventaire général du patrimoine culturel

44 Les constructions d'église sont recherchées par les architectes qui voient l'occasion de réaliser une œuvre originale. En 1961, le centre paroissial de Ménival ${ }^{54}$ a fait l'objet d'un concours ouvert; 11 projets sont alors déposés ${ }^{55}$. Le programme met en exergue les demandes de l'O.D.P.N. : "Beauté atteinte surtout par la sincérité dans l'emploi du matériau choisi et la netteté dépouillée des lignes auxquelles conduit la technique de mise en ceuvre...

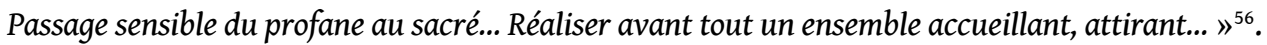


Le diocèse insistant sur les caractères de sobriété et de simplicité que devaient présenter les bâtiments, certains architectes vont porter leur travail sur les plans dont l'originalité va marquer leur œuvre tout en offrant des solutions aux nouvelles prescriptions liturgiques (autel face au peuple, rapprochement des célébrants et des fidèles, importance de la parole.... ${ }^{57}$. À Sainte-Anne de Ménival ${ }^{58}$, Paul Curtelin propose un décagone ponctué de contreforts (fig. $\left.\mathbf{n}^{\circ} \mathbf{1 1}\right)$; Saint-François d'Assise (9e), Notre-Dame-de-Lourdes (Bron) adoptent des plans octogonaux, Notre-Dame du Point-du-Jour ${ }^{59}$, un plan en éventail (fig. $\mathbf{n}^{\circ}$ 12) et Notre-Dame du Roule (La Mulatière) un plan en ellipse.

Figure 11

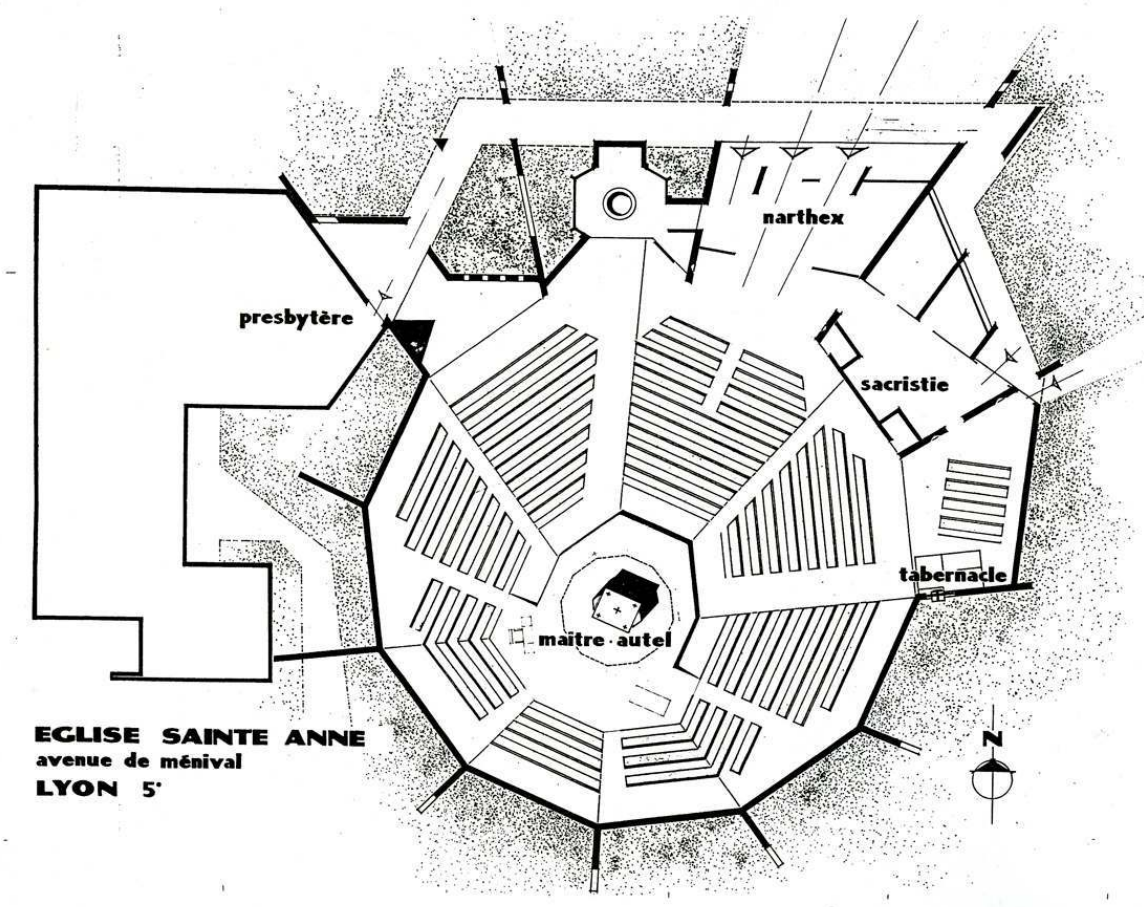

Église Sainte-Anne de Ménival. Plan / Paul Curtelin (A. privées)

Phot. M. Chalabi, 2006. @ Région Rhône-Alpes, Inventaire général du patrimoine culturel 
Figure 12

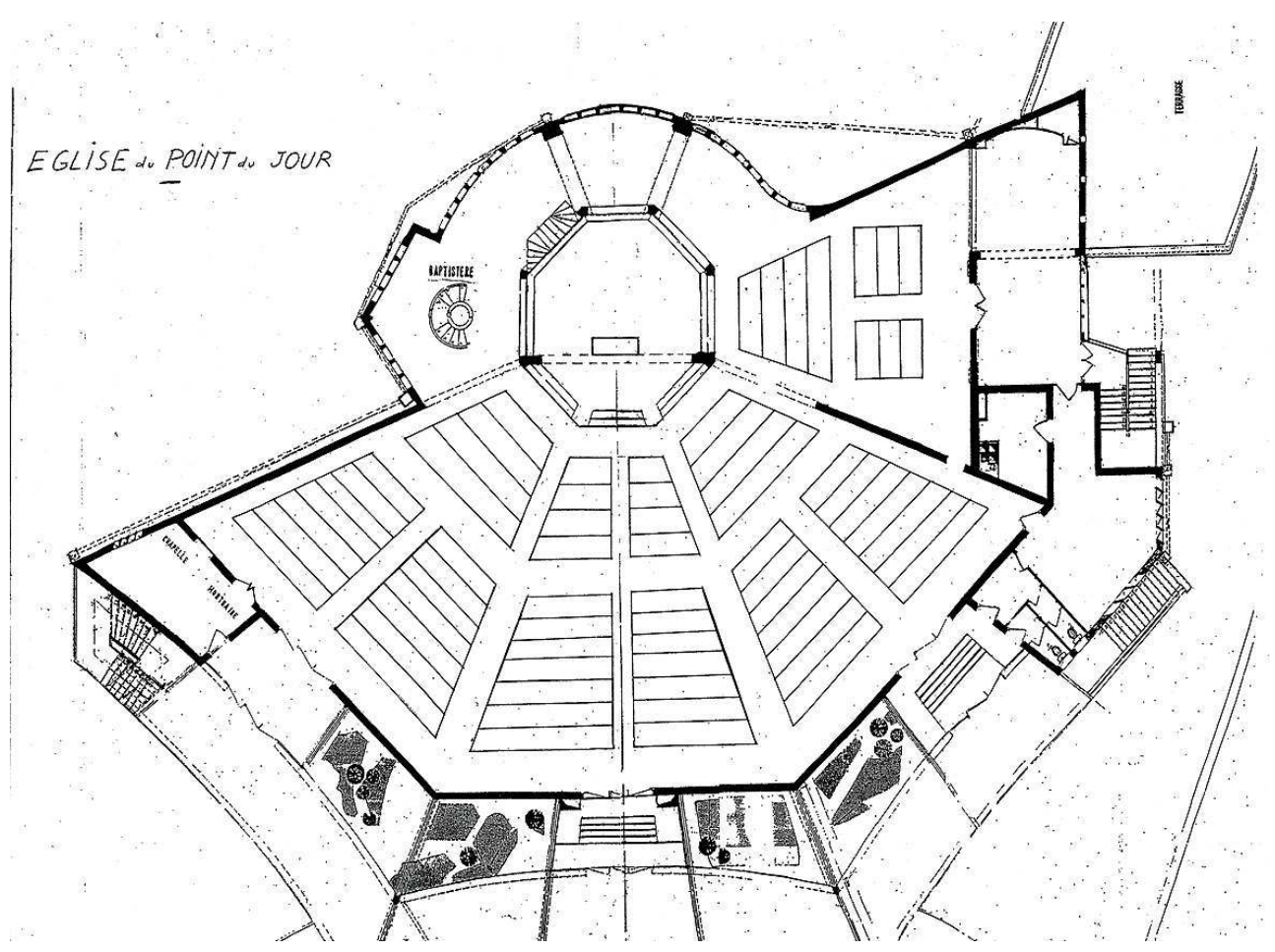

Église Notre-Dame du Point-du-Jour. Plan. Schéma (A. paroissiales)

Phot. M. Chalabi, 2006. (C) Région Rhône-Alpes, Inventaire général du patrimoine culturel

Le quartier de la Duchère est pratiquement un cas d'école ${ }^{60}$. Le plan masse établi par la SERL prévoit quatre lieux de culte, qui comprendront chacun une église, des salles de catéchisme et de réunions et un presbytère : l'église principale, dite du Plateau ${ }^{6162}$, pour un quartier de 9000 habitants (2250 logements), confiée à l'architecte principal du projet François-Régis Cottin, l'église de Balmont (5000 habitants, 1200 logements) attribuée à Pierre Genton, l'église du Château (2500 habitants, 600 logements) à Maurice Novarina, et celle de la Sauvegarde (5000 habitants) qui sera confiée à Charles Tolot. Mais il n'y a qu'une paroisse Notre-Dame et les églises ne reçoivent pas d'autre vocable. Chaque architecte propose sa solution pour intégrer l'édifice dans un quartier fortement marqué par un urbanisme en hauteur, mais tous privilégient des édifices bas, voire enterrés. L'église du Château affiche un parti cubique, peu ajouré, où l'aspect massif des deux premiers niveaux est allégé par la bande vitrée qui sépare le haut des murs de la charpente. L'église de Balmont, construite sur un plan triangulaire arrondi à la base, à demi enterrée, est surmontée par la pyramide d'un lanterneau. L'église du Plateau, baptisée Notre-Dame du Monde entier, est entourée d'un talutement qui rappelle le fort militaire démoli pour la construction de la cité (fig. $\mathbf{n}^{\circ} \mathbf{1 3}$ ). 
Figure 13

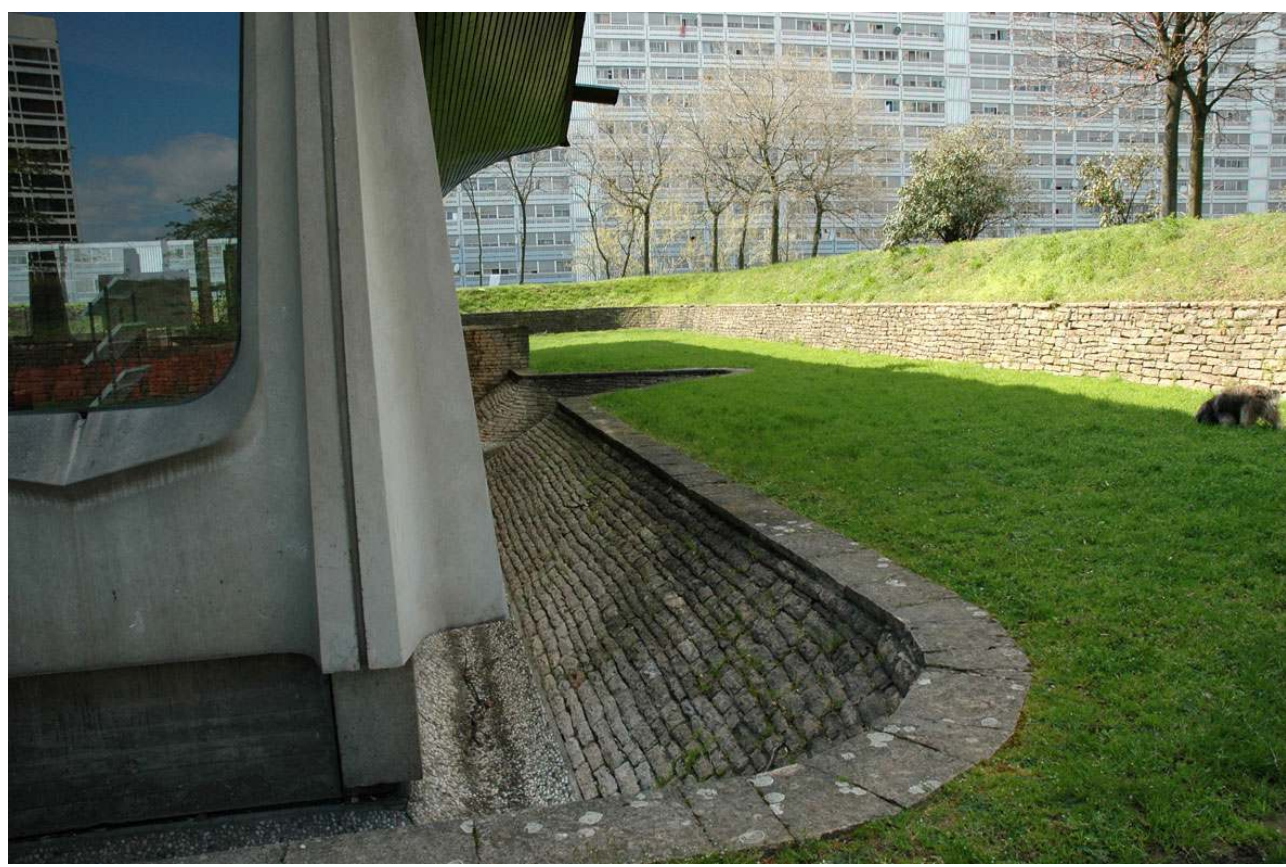

Église Notre-Dame du Monde entier, Le Plateau, La Duchère. Le glacis

Phot. M. Chalabi, 2006. (c) Région Rhône-Alpes, Inventaire général du patrimoine culturel.

Le premier numéro de la revue L'Art sacré paru après la guerre rappelait les principes énoncés par le père Régamey: il faut que l'église apparaisse spontanément comme un édifice religieux, son caractère doit la désigner comme «l'habitation de Dieu et la maison de prière».

Le colloque de l'UNESCO de 1965 reprenait les mêmes principes, se fondant sur une enquête réalisée auprès de 120 prêtres de grands ensembles et quartiers neufs qui soulignait le besoin d'un signe religieux visible ${ }^{63}$. Les conclusions du ministre É. ClaudiusPetit revenaient sur l'idée d'église-monument : « il faut réhabiliter le mot et la chose... il ne faut pas renoncer à faire des monuments sacrés à côté des autres monuments humains de la ville. Et il serait scandaleux de renoncer à en faire des ceuvres d'art... ». Commentant les travaux du colloque, un des rédacteurs de l'Art sacré, J. Capcir, écrivait « ... Urbanistes et architectes ont tendance à voir dans l'église... un élément privilégié de leur composition d'ensemble,...l'ouvre idéale dans laquelle pourra s'exprimer totalement leur besoin de création... Disons le tout net, il n'est aucune raison pour demander aux chrétiens de payer aux architectes ces fantaisies coûteuses... et laides... Les prêtres des grands ensembles ... sentent qu'une église importante y serait non seulement anachronique, mais souvent scandaleuse... Ils refusent absolument l'idée de l'églisemonument " artistique »... Mais peut-on les suivre lorsqu'ils vont jusqu'à affirmer " quatre murs et un toit suffisent »?... Soyons donc pauvres dans le choix des dimensions et des matériaux, mais ne soyons pas avares d'imagination créatrice... $»^{64}$.

En 1969, dans la préface du Guide des églises nouvelles en France, Mgr G. de Vaumas, président du Comité national de construction d'églises, précise cette idée : «Les formes extérieures ont constitué depuis des siècles des signes valables. Mais à l'égard de nos contemporains, ces signes évoquent une Église qui ne se serait pas renouvelée... Sans style propre, les églises et les équipements annexes, absolument indispensables à l'activité des communautés chrétiennes pour leur témoignage à l'égard du monde, doivent se définir 
comme des lieux de silence, de recueillement, de liens humains, d'ouverture à l'au-delà de la cité humaine... $»^{65}$. Dans le même ouvrage, l'auteur oppose l'idée de " maison de Dieu » à celle de la "maison d'église ", qu'il définit comme "maison de la communauté, ... symbole du rassemblement, ... cité de paix... ». Il reprend le message du cardinal Lercaro aux artistes de Cologne en 1968 « Nous ne prétendons pas construire des églises pour les siècles à venir, mais nous nous limitons à faire des églises modestes et fonctionnelles qui nous servent à nous et en face desquelles nos fils se sentiront libres de les repenser à nouveau, de les abandonner, de les modifier comme le voudra leur époque et leur sensibilité religieuse... L'Église du Seigneur peut donc être vraiment une tente mobile que l'Esprit pose où il veut et dont les formes doivent être continuellement réinventées par les hommes attentifs à l'Esprit... ».

Le programme architectural, l'aménagement intérieur, la décoration doivent répondre à ces principes et aux exigences liturgiques.

\section{Figure 14}

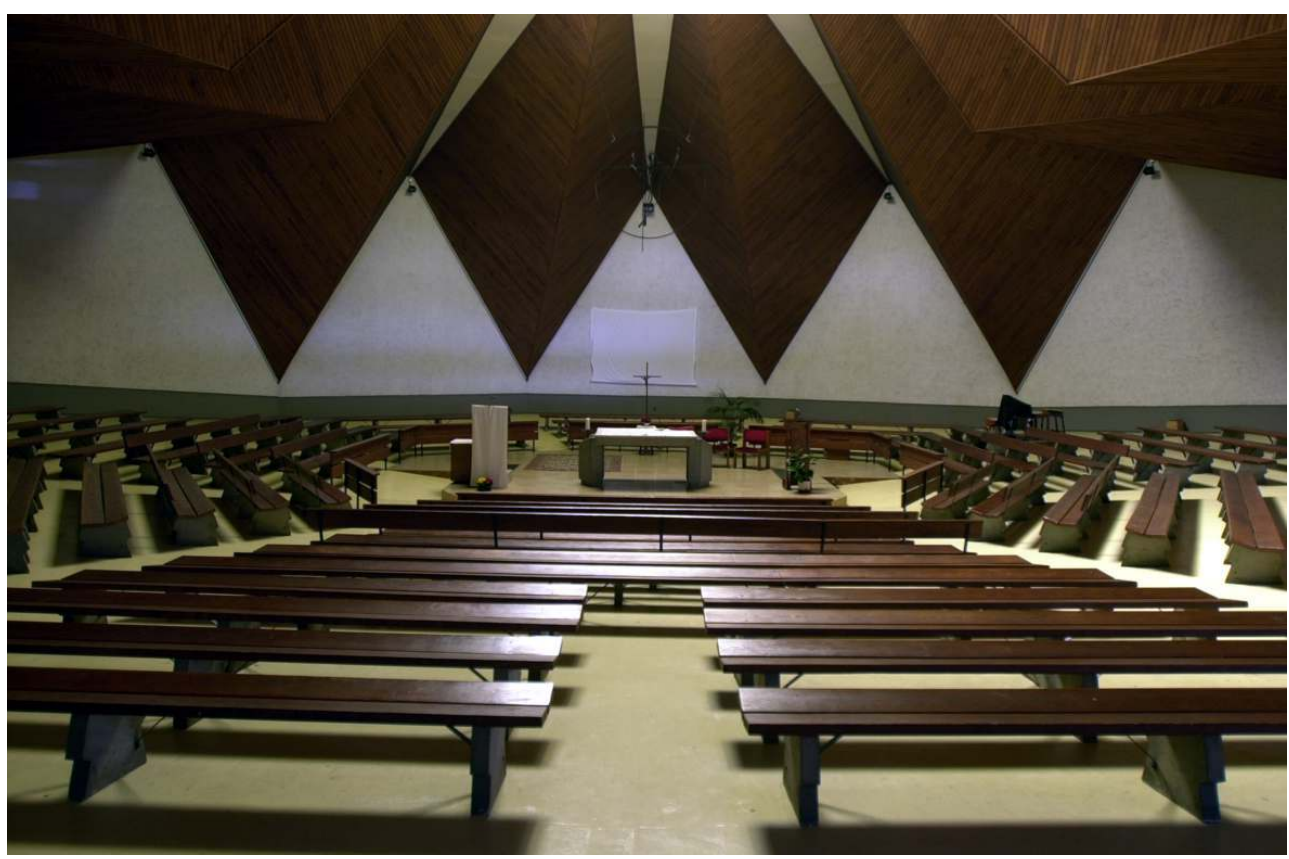

Église Sainte-Anne de Ménival. Vue d'ensemble de la nef

Phot. M. Chalabi, 2006. (C) Région Rhône-Alpes, Inventaire général du patrimoine culturel 


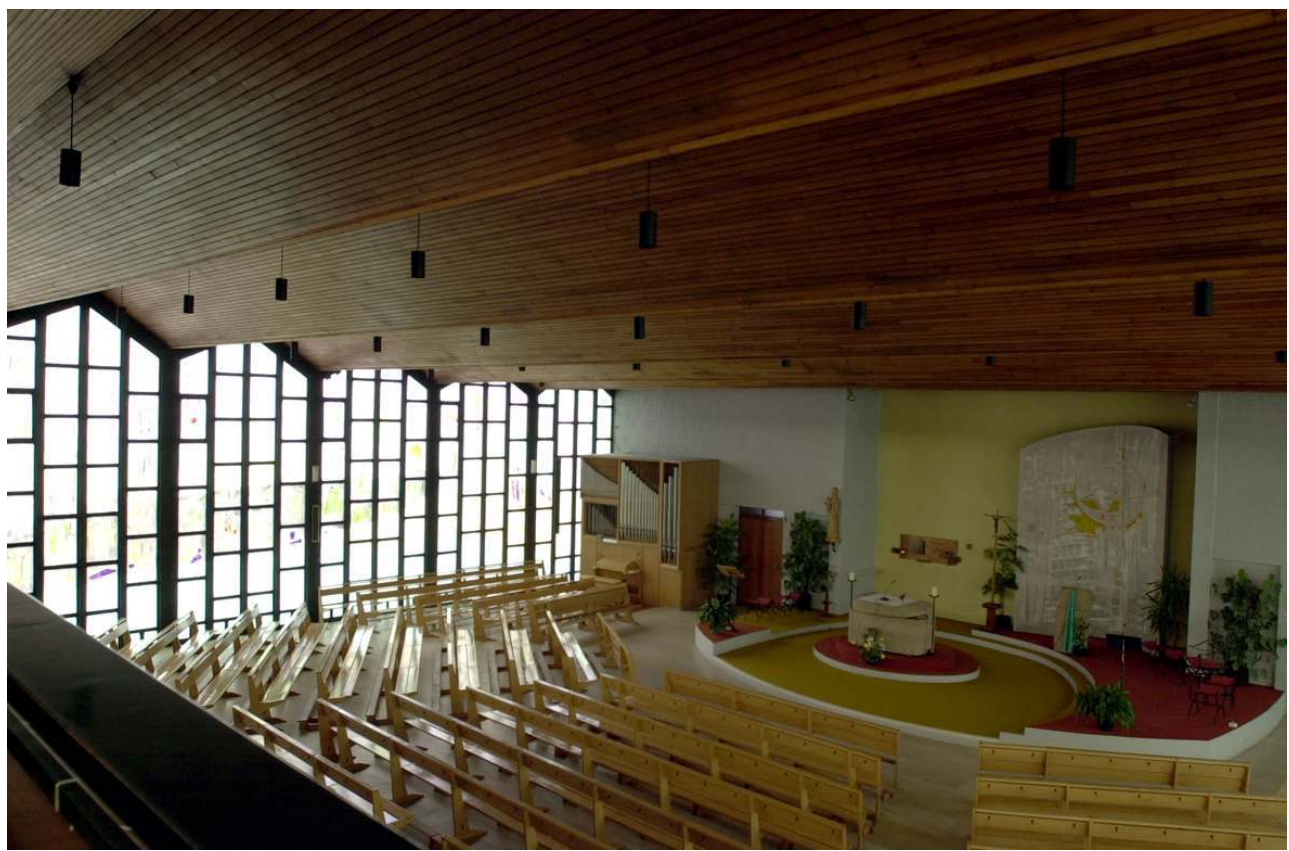

Église Saint-Luc, Sainte-Foy-les-Lyon. Vue d'ensemble de la nef

Phot. M. Chalabi, 2006. (c) Région Rhône-Alpes, Inventaire général du patrimoine culturel

Avec l'abandon du plan en croix, la séparation entre nef et sanctuaire ne se matérialise plus que par les quelques marches qui les séparent. Les architectes la renforcent par une intensité lumineuse focalisée sur le sanctuaire : toute l'attention du fidèle doit être attirée vers l'autel, qui doit concentrer le maximum de sources lumineuses. Le programme de Sainte-Anne de Ménival ${ }^{66}$ le précise : «Grand autel : 1. permettant la messe dans les deux sens; 2. se situant au centre de convergence a. d'une part de l'attention des fidèles - plan éventail, $b$. d'autre part de l'orientation des sources lumineuses » (fig. $\left.\mathbf{n}^{\circ} \mathbf{1 4}\right)$. Cette source peut provenir de parois latérales entièrement vitrées comme à Sainte-Marie de la Guillotière ${ }^{67}$ (grand vitrail de la Vierge au sud ${ }^{68}$ ) ou Saint-Luc ${ }^{69}$ (fig. $\mathbf{n}^{\circ}$ 15), par des vitraux disposés dans l'abside (Saint-Michel de Berthelot) ${ }^{7071}$, Notre-Dame du Point-du-Jour ${ }^{72}$, des claires voies ou des flèches de lumière (Saint-Jean Apôtre ${ }^{73}$ ) (fig. $\mathbf{n}^{\circ}$ 16), l'Annonciation à Vaise ${ }^{7775}$. 


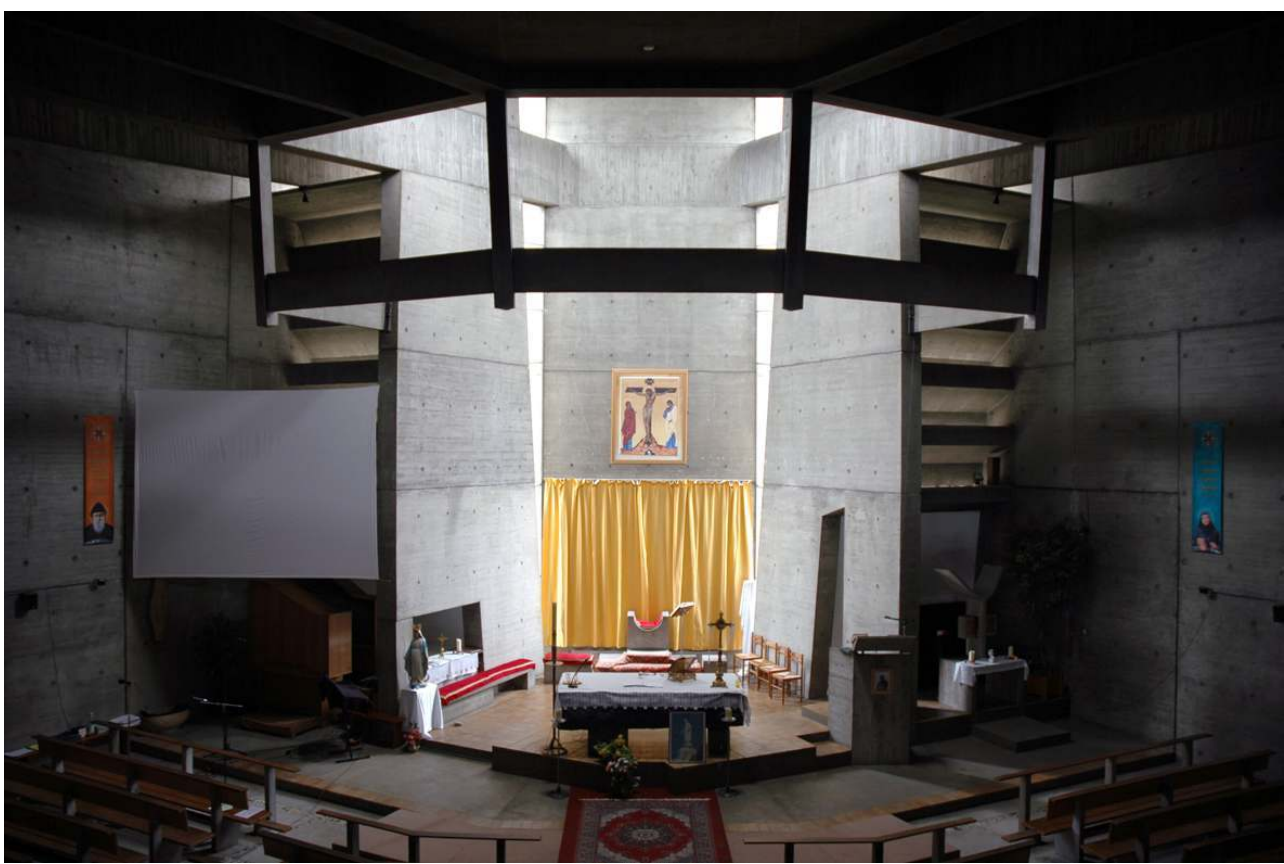

Église Saint-Jean-Apôtre. Le chœur. Aménagement modifié pour le culte maronite Phot. M. Chalabi, 2008. @ Région Rhône-Alpes, Inventaire général du patrimoine culturel

Figure 17

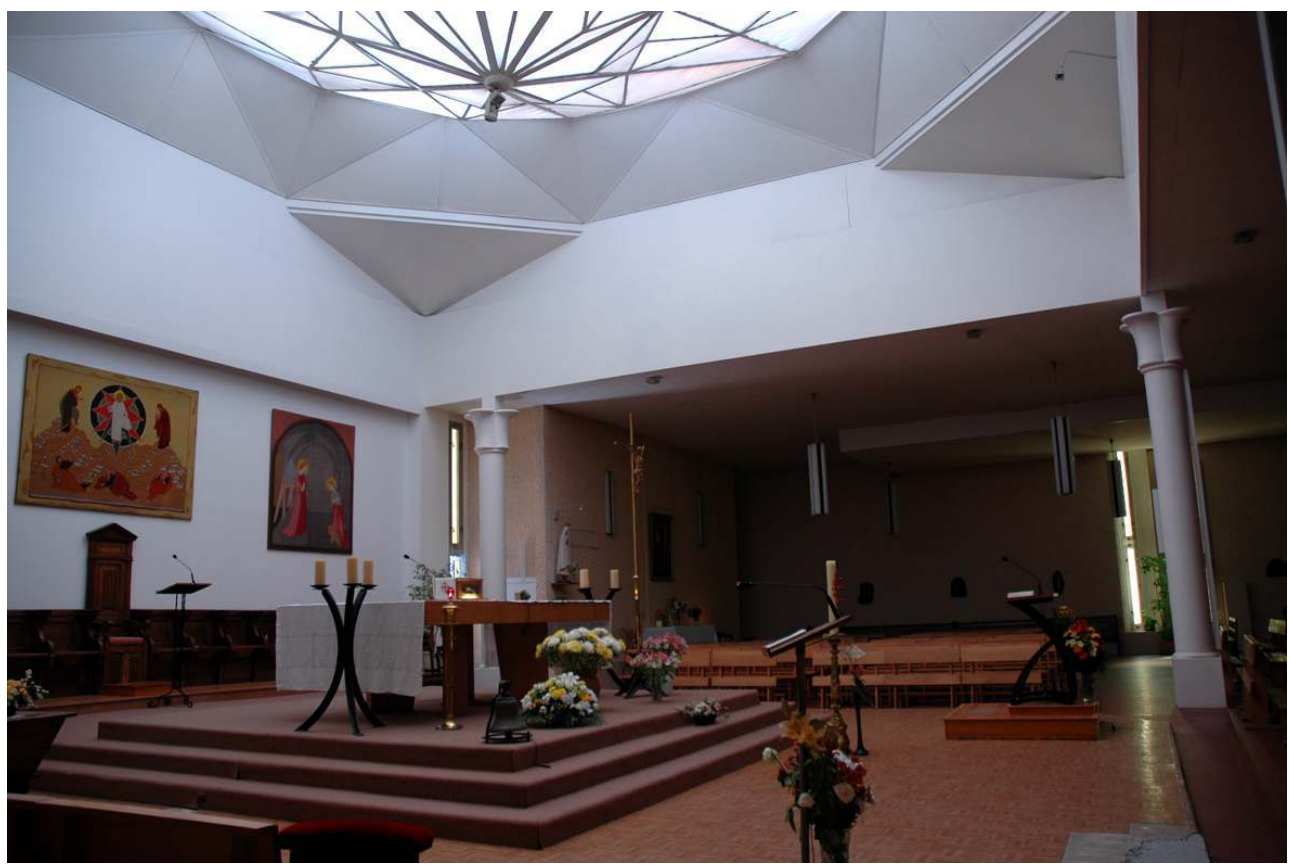

Église de la Sainte-Trinité. Le « diamant » du lanterneau éclairant le chœur

Phot. M. Chalabi, 2008. @ Région Rhône-Alpes, Inventaire général du patrimoine culturel

Une disposition particulièrement appréciée des architectes est celle du lanterneau disposé au-dessus du sanctuaire; c'est l'option prise par P. Genton à la Sainte-Trinité ${ }^{76}$ (fig. $\mathbf{n}^{\circ} \mathbf{1 7 )}$, reprise à l'église de Balmont et à celle de Notre-Dame d'Espérance 
(Villeurbanne), adoptée également par P. Curtelin à Sainte-Anne de Ménival ${ }^{77}$ (fig. $\mathbf{n}^{\circ} \mathbf{1 8}$, $\mathbf{n}^{\circ}$ 19) et E. Agniel à Notre-Dame du Roule (La Mulatière).

Figure 18

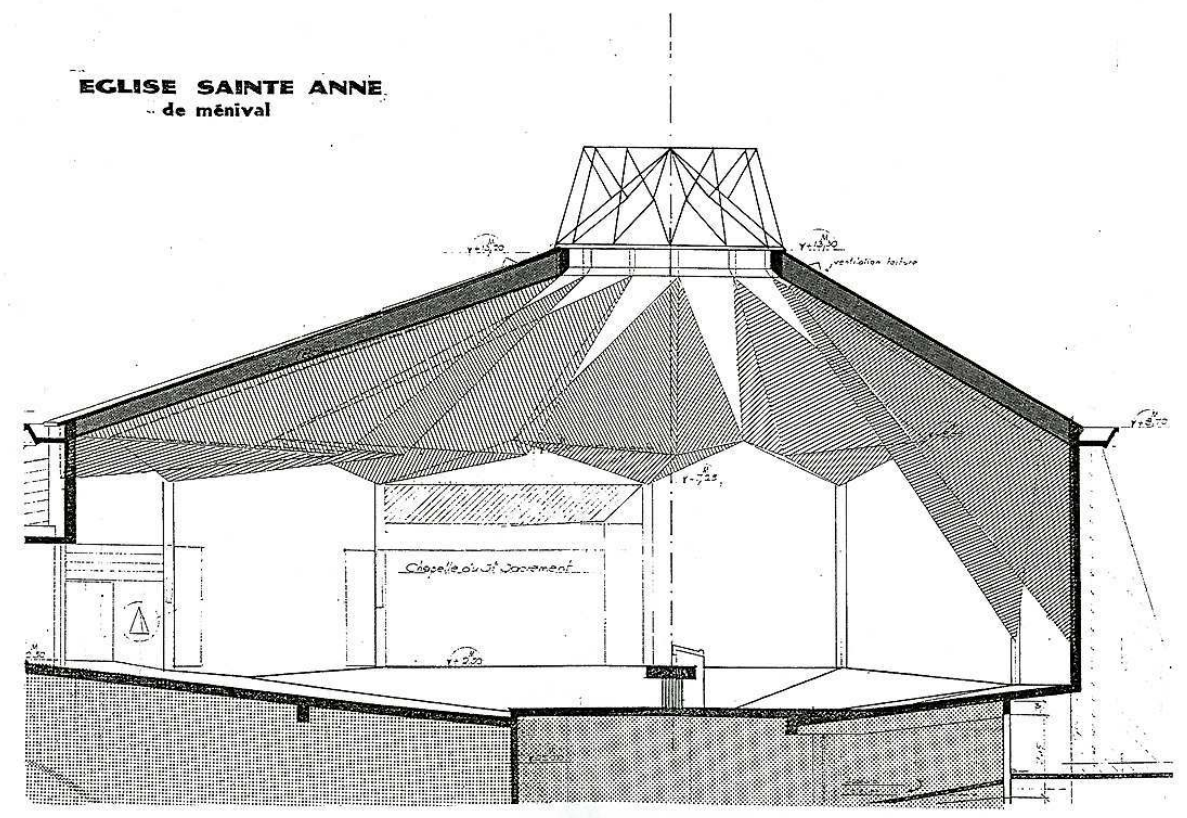

Église Sainte-Anne de Ménival. Coupe / P. Curtelin (A. privées)

Phot. M. Chalabi, 2008. (C) Région Rhône-Alpes, Inventaire général du patrimoine culturel 


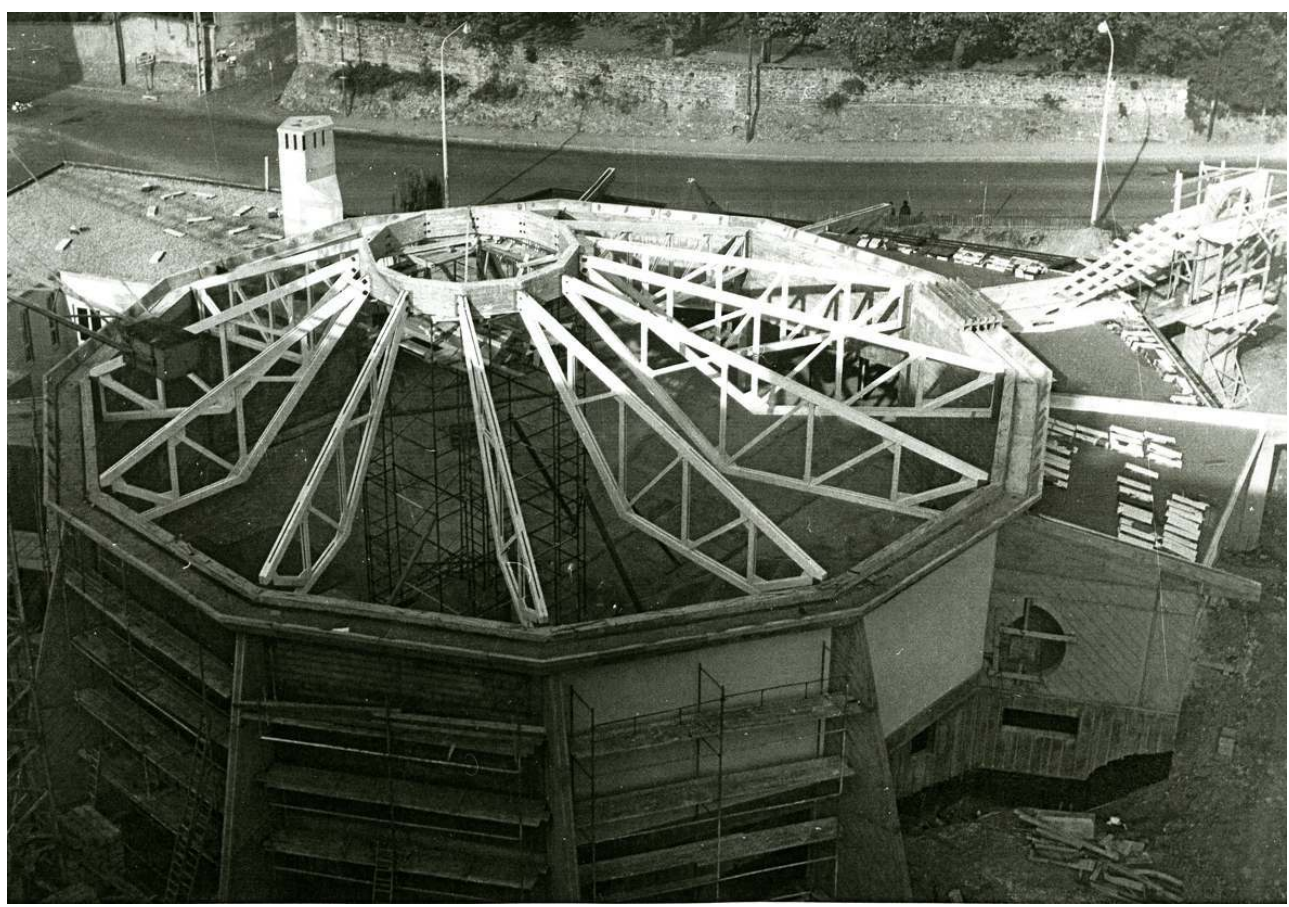

Église Sainte-Anne de Ménival. La charpente et le lanterneau en construction

Photogr. P. Curtelin (A. privées)

Phot. M. Chalabi, 2008. (C) Région Rhône-Alpes, Inventaire général du patrimoine culturel

53 L'église, lieu de recueillement, est aussi un lieu d'accueil. Les théoriciens de l'art sacré souhaitaient que les traditions du porche, où les fidèles se rassemblent, du narthex où ils se préparent à entrer dans le lieu sacré, soient transformées mais maintenues. Les porches sont assez rares $(23 \%)$ et souvent de petites dimensions (Annonciation de Vaise ${ }^{78}$ ${ }^{79}$, Saint-Charles de Serin ${ }^{80}$ (voir fig. $\mathbf{n}^{\circ} \mathbf{3}$ ), Sainte-Thérèse de la Plaine) ; ils sont souvent $(43 \%)$ remplacés par des auvents (Saint-Michel de Berthelot ${ }^{81}$, Sainte-Élisabeth ${ }^{82}$ (voir fig. $\mathbf{n}^{0}$ 6), Sainte-Marie de la Guillotière ${ }^{83}$ (voir fig. $\mathbf{n}^{\circ}$ 1). À Saint-Jean Apôtre ${ }^{84}$ l'accueil des $^{\prime}$ fidèles est particulièrement soigné : un portique ouvrant sur les deux voies d'accès à l'église conduit les fidèles jusqu'aux deux portes d'entrée séparées par le baptistère, chaque porte ouvrant sur un vestibule aménagé entre ce baptistère et la sacristie d'un côté, la chapelle de semaine de l'autre (fig. $\mathbf{n}^{\circ} \mathbf{2 0}$ ). Selon les dispositions des terrains ou la nécessité d'aménager des salles de réunion ou de catéchisme au rez-de-chaussée, quelques églises sont accessibles par une montée d'escalier (Saint-Michel ${ }^{85}$, Sainte-Trinité ${ }^{86}$, Saint-Julien de Cusset, Notre-Dame du Point-du-Jour ${ }^{87}$ ) (fig. $\mathbf{n}^{\circ} \mathbf{2 1}$ ), qui pose des problèmes d'adaptation du bâtiment à un accès pour tous ; les solutions proposées ne sont pas toujours du meilleur effet esthétique (à Saint-Michel, ascenseur débouchant directement dans la nef). Une petite majorité d'églises (53\%) disposent d'un narthex, véritable espace liturgique accueillant baptistère et chapelle mortuaire comme à SaintCharles de Serin ${ }^{88}$, mais le plus souvent hall d'entrée fermé comme à Sainte-Marie de la Guillotière $^{89}$, Sainte Anne de Ménival ${ }^{90}$, Saint-Luc ${ }^{91}$, et au Plateau ${ }^{9293}$. 

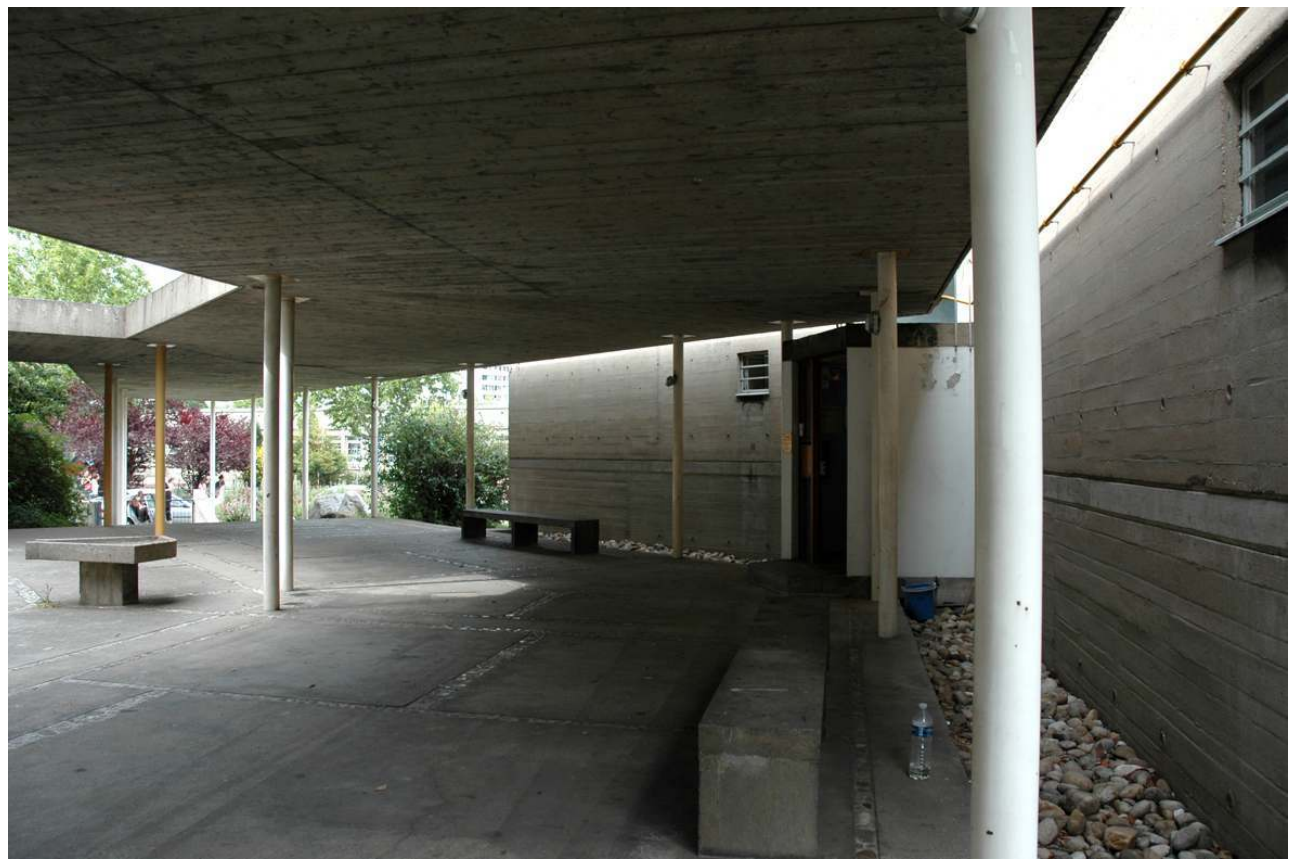

Église Saint-Jean-Apôtre. Le portique

Phot. M. Chalabi, 2008. @ Région Rhône-Alpes, Inventaire général du patrimoine culturel

Figure 21

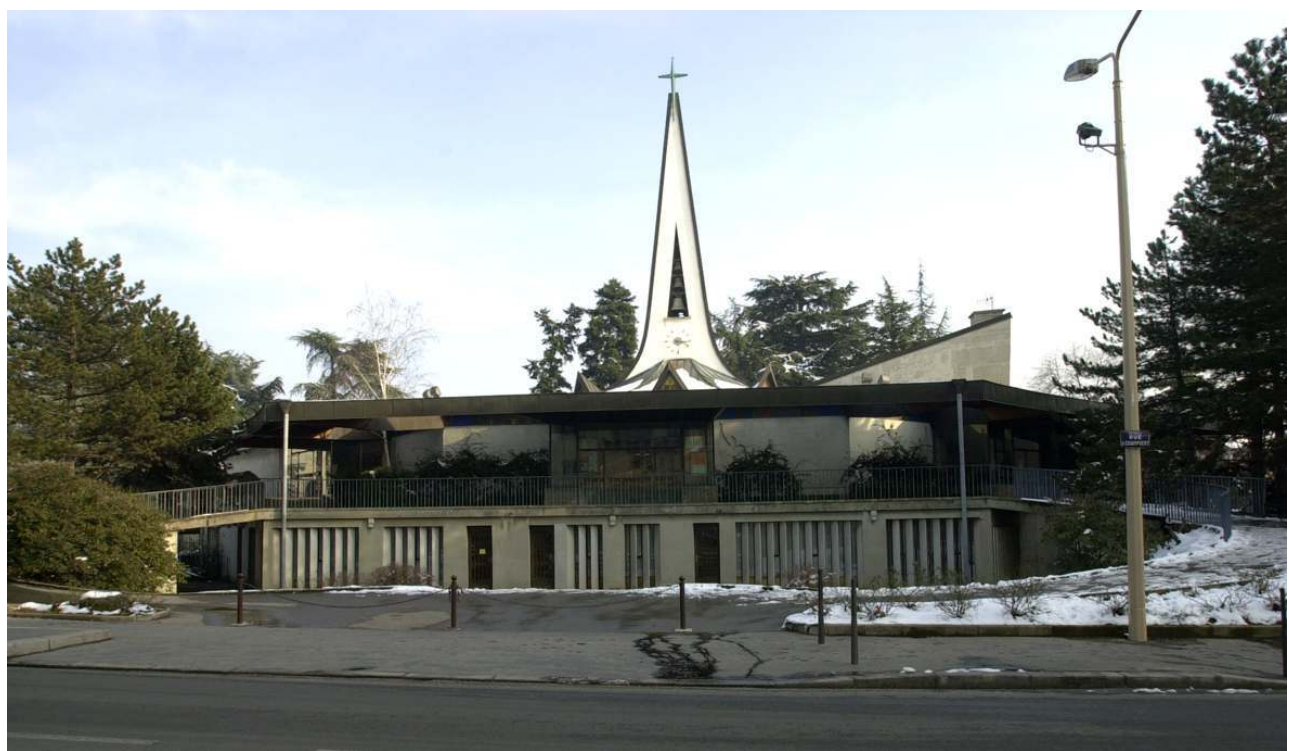

L'église Notre-Dame du Point-du-Jour construite en contrebas, avec les salles de catéchisme au rezde-chaussée, l'église à l'étage

Phot. M. Chalabi, 2006. @ Région Rhône-Alpes, Inventaire général du patrimoine culturel

Lyon figure parmi les diocèses précurseurs en matière d'évolution liturgique : le père Laurent Rémilleux, curé de Notre-Dame de Saint-Alban à partir de 1924, avait obtenu du cardinal Gerlier l'autorisation de dire la messe en français, face au peuple, associant déjà l'assemblée à la célébration ${ }^{94}$. 
Figure 22

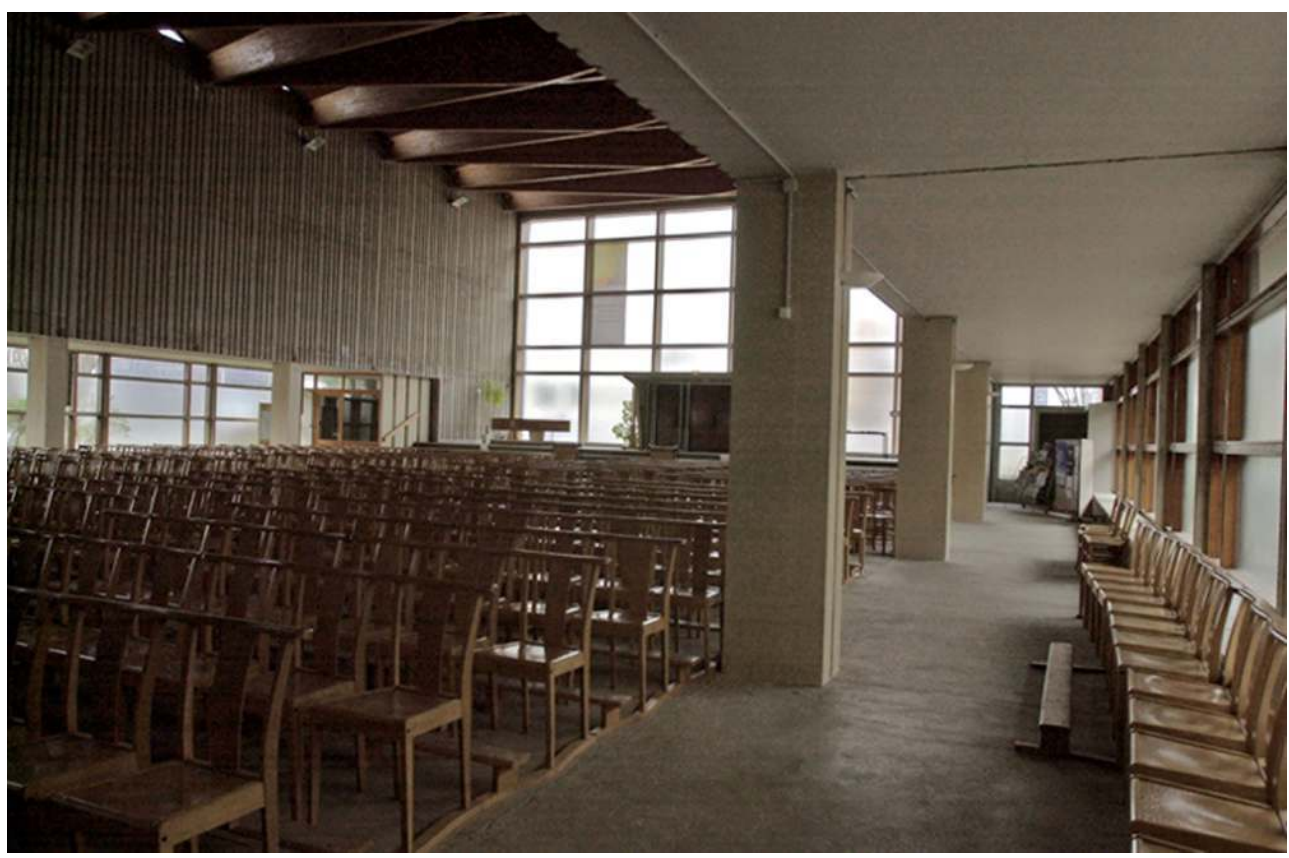

Église Sainte-Élisabeth. Vue d'ensemble de la nef

Phot. M. Chalabi, 2006. @ Région Rhône-Alpes, Inventaire général du patrimoine culturel

Figure 23

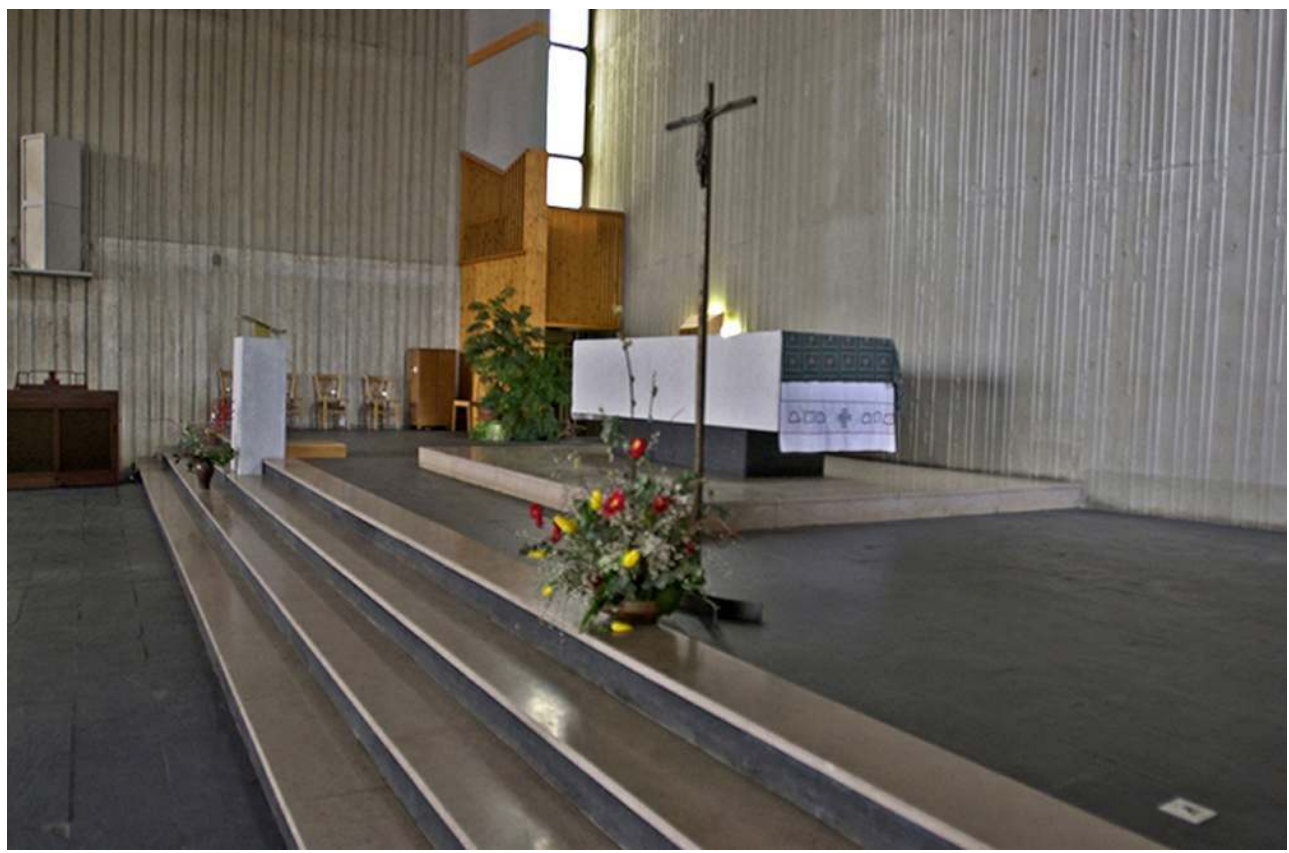

Église Sainte-Élisabeth. Le chœur

Phot. M. Chalabi, 2006. (C) Région Rhône-Alpes, Inventaire général du patrimoine culturel

Cependant, la majorité des églises construites dans la seconde moitié du siècle conserve une disposition un peu théâtrale de l'autel, placé sur une estrade de 3 ou 4 marches (parfois plus comme à Saint-Michel ${ }^{95}$ ou Sainte-Élisabeth ${ }^{96}$ (fig. $\mathbf{n}^{\circ} \mathbf{2 2}, \mathbf{n}^{\circ}$ 23), au fond de 
l'église, devant le mur du chevet, ou dans l'angle lorsque le plan est carré (le Château). Dans peu d'églises, le sanctuaire occupe une place plus centrée permettant de grouper les fidèles à l'entour (Notre-Dame du Point-du-Jour ${ }^{97}$ (voir fig. $\mathbf{n}^{\circ}$ 12), Sainte-Anne de Ménival $^{98}$ (voir fig. $\mathbf{n}^{\circ} 11, \mathbf{n}^{\circ} 14$ ), Saint-Luc ${ }^{99}$ (voir fig. $\mathbf{n}^{\circ} 15$ ), la Sainte-Trinité ${ }^{100}$ (voir fig. $\mathbf{n}^{\circ}$ 17), Notre-Dame du Monde entier ${ }^{101102}$ ). Paul Curtelin souligne l'importance de cette position de l'autel : "...Si l'autel n'avait pu être décentré, l'Assemblée aurait été coupée en quartiers; l'unité communautaire n'aurait pu se concrétiser... La position de l'autel permet la pénétration des célébrants au milieu des "participants"; installés au milieu d'eux, ils peuvent mieux les exhorter et les enseigner... Toutes les structures de l'église obéissent au même souci : faire converger l'Assemblée vers l'autel... $»^{103}$. À Notre-Dame du Point-du-Jour ${ }^{104}$, les poutres lamellé-collé qui soutiennent la couverture, les grandes arcades en béton qui entourent le sanctuaire éclairé à l'arrière par les vitraux de l'abside, concentrent l'attention de l'assemblée vers l'autel majeur (fig. $\mathbf{n}^{\circ} \mathbf{2 4}$ ).

Figure 24

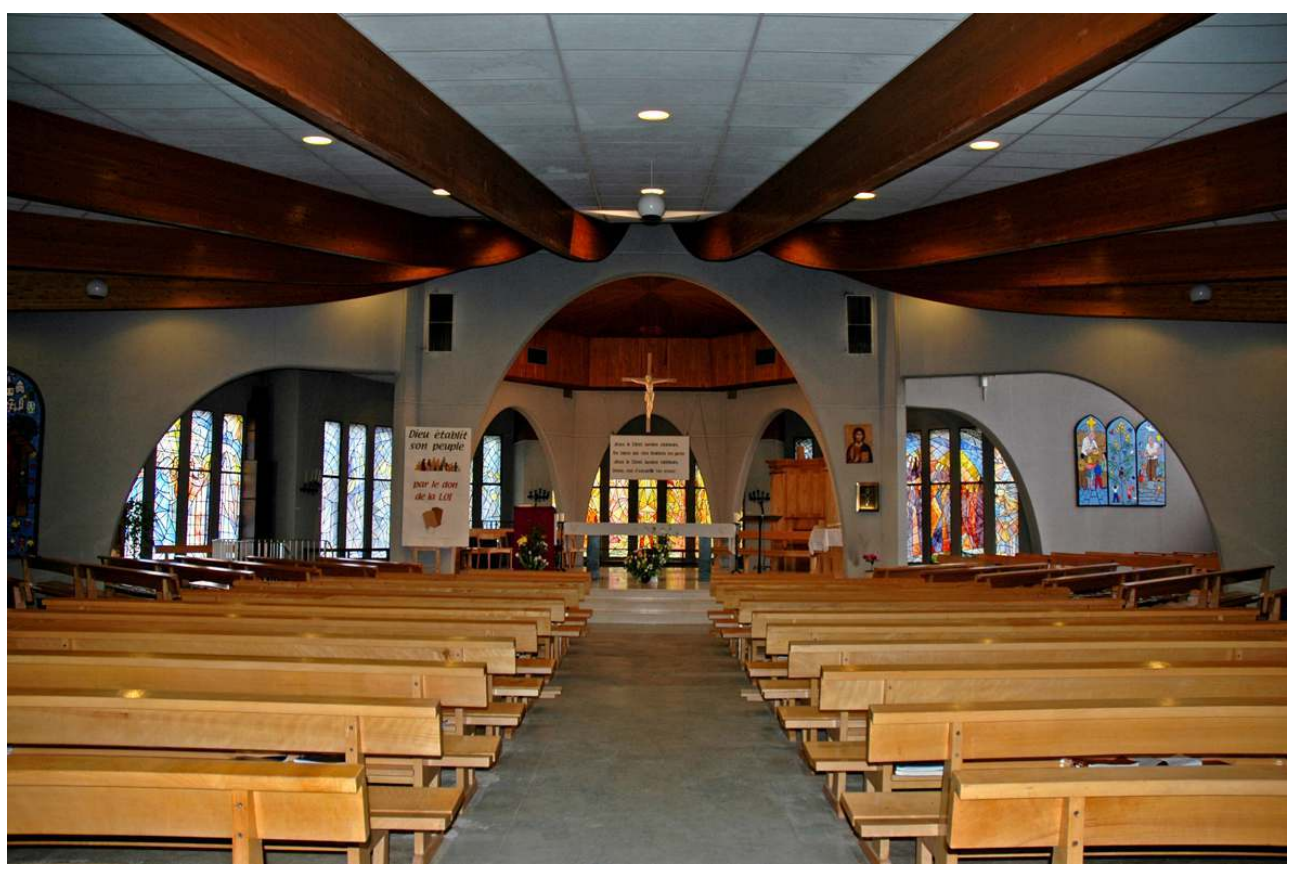

Église Notre-Dame du Point-du-Jour. Vue d'ensemble du chœur

Phot. M. Chalabi, 2006. @ Région Rhône-Alpes, Inventaire général du patrimoine culturel 
Figure 25

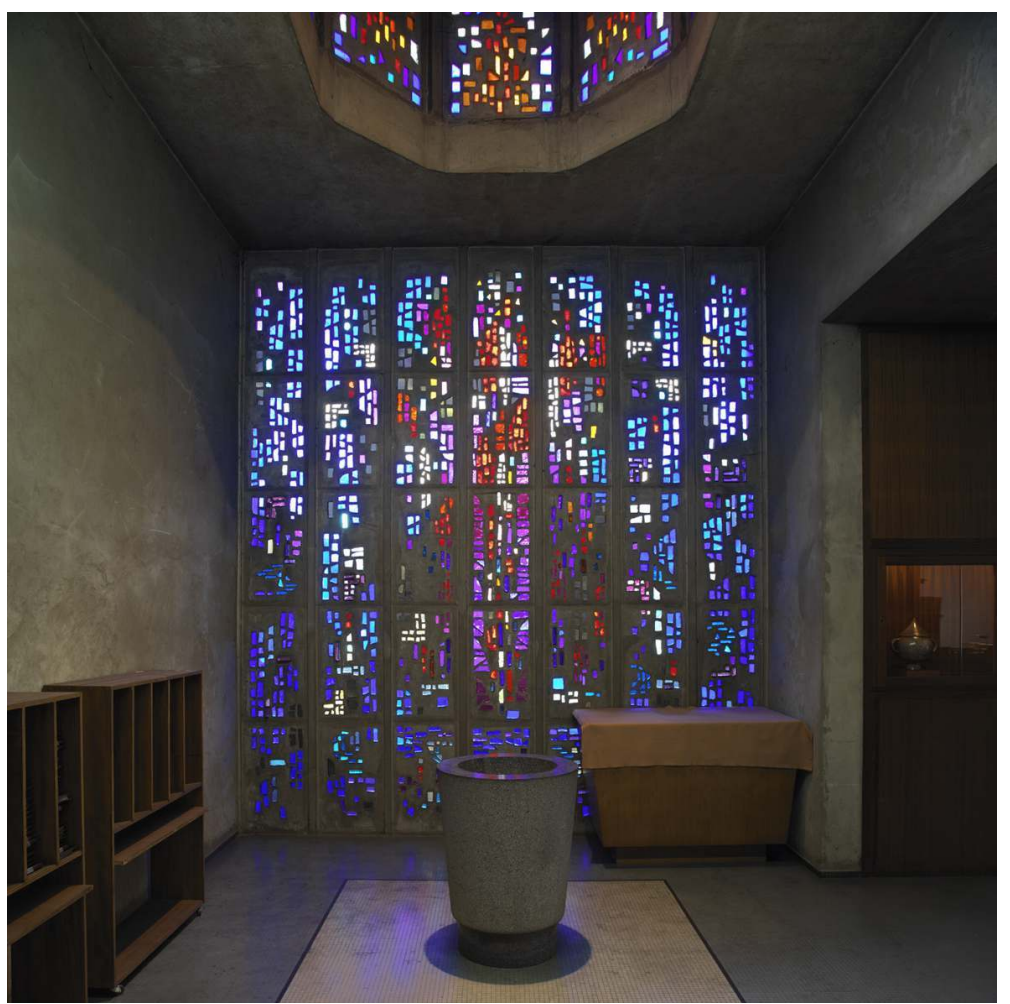

Église Sainte-Marie-de-la Guillotière. La chapelle baptismale éclairée des vitraux de Paulin-Besson Phot. É. Dessert, 2006. @ Région Rhône-Alpes, Inventaire général du patrimoine culturel

Le baptistère est également un espace liturgique fortement marqué par l'évolution liturgique. Les instructions du diocèse de 1959 ne recommandaient qu'une «simple cuve, placée en principe dans un local extérieur, sinon dans un emplacement réservé au fond du lieu de culte ${ }^{105}$. Par la suite, on insiste sur le baptême, célébration collective; le lien entre baptême et eucharistie doit être matérialisé ${ }^{106}$; le retour au baptême par immersion est envisagé, ainsi que le lien avec une source d'eau vive. Architectes et curés bâtisseurs se sont efforcés de suivre ces prescriptions avec plus ou moins de réussite. L'usage de la chapelle baptismale est maintenu à l'Annonciation de Vaise ${ }^{107108}$, Saint-Charles de Serin ${ }^{109}$, Sainte-Marie de la Guillotière ${ }^{110}$ (fig. $\mathbf{n}^{\circ}$ 25). À la Sainte-Trinité ${ }^{111}$, la cuve baptismale ${ }^{112}$, de grande taille, reste un meuble posé dans la première travée de la nef; cependant l'entrée de l'église étant latérale par rapport à la nef, il y a un changement de direction dans le cheminement des fidèles, entre l'entrée, le baptistère et l'autel. À Sainte-Élisabeth ${ }^{113}$, Saint-Michel ${ }^{114}$, les fonts baptismaux sont aménagés dans l'entrée (fig. $\mathbf{n}^{\circ} \mathbf{2 6}, \mathbf{n}^{\circ} \mathbf{2 7}$ ). 
Figure 26

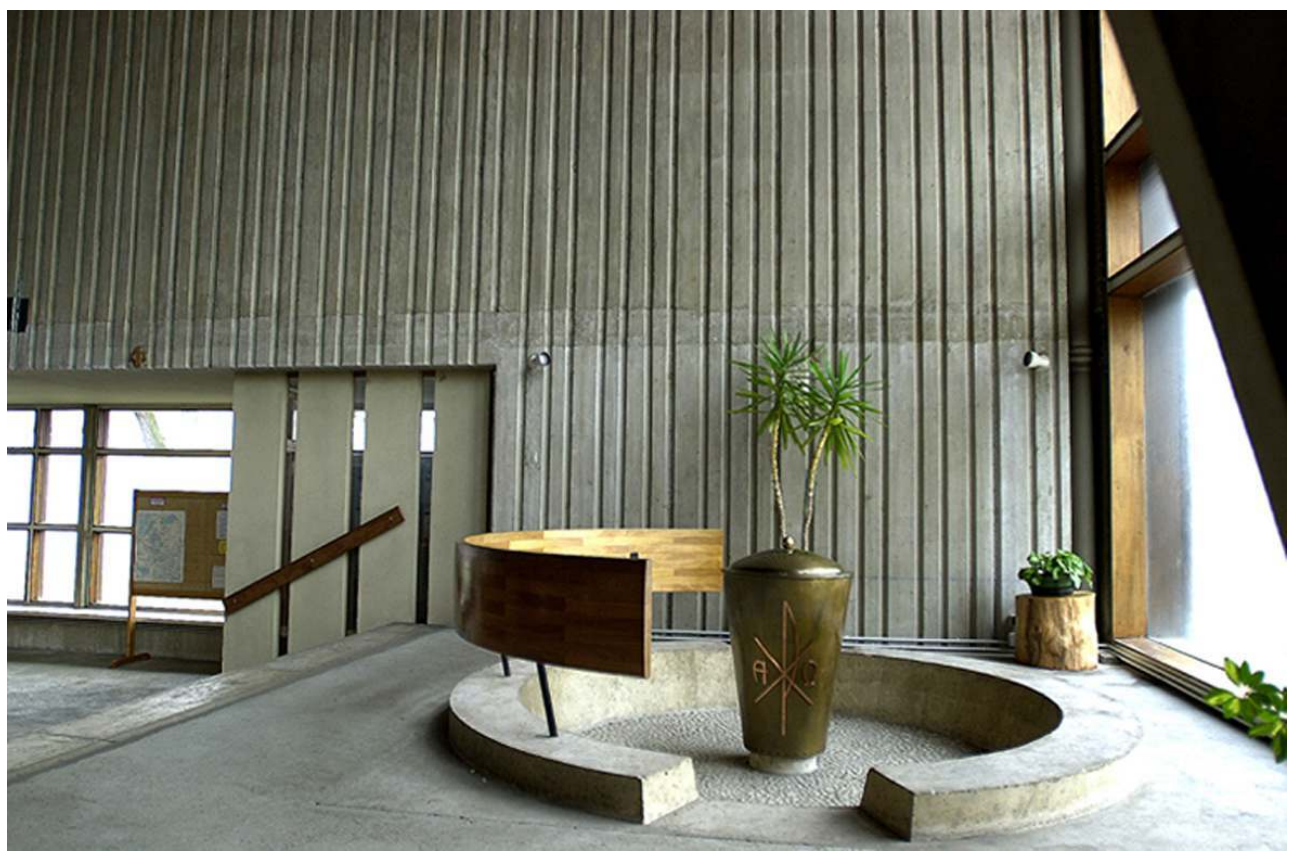

Église Sainte-Élisabeth. Les fonts baptismaux

Phot. M. Chalabi, 2006. @ Région Rhône-Alpes, Inventaire général du patrimoine culturel

Figure 27

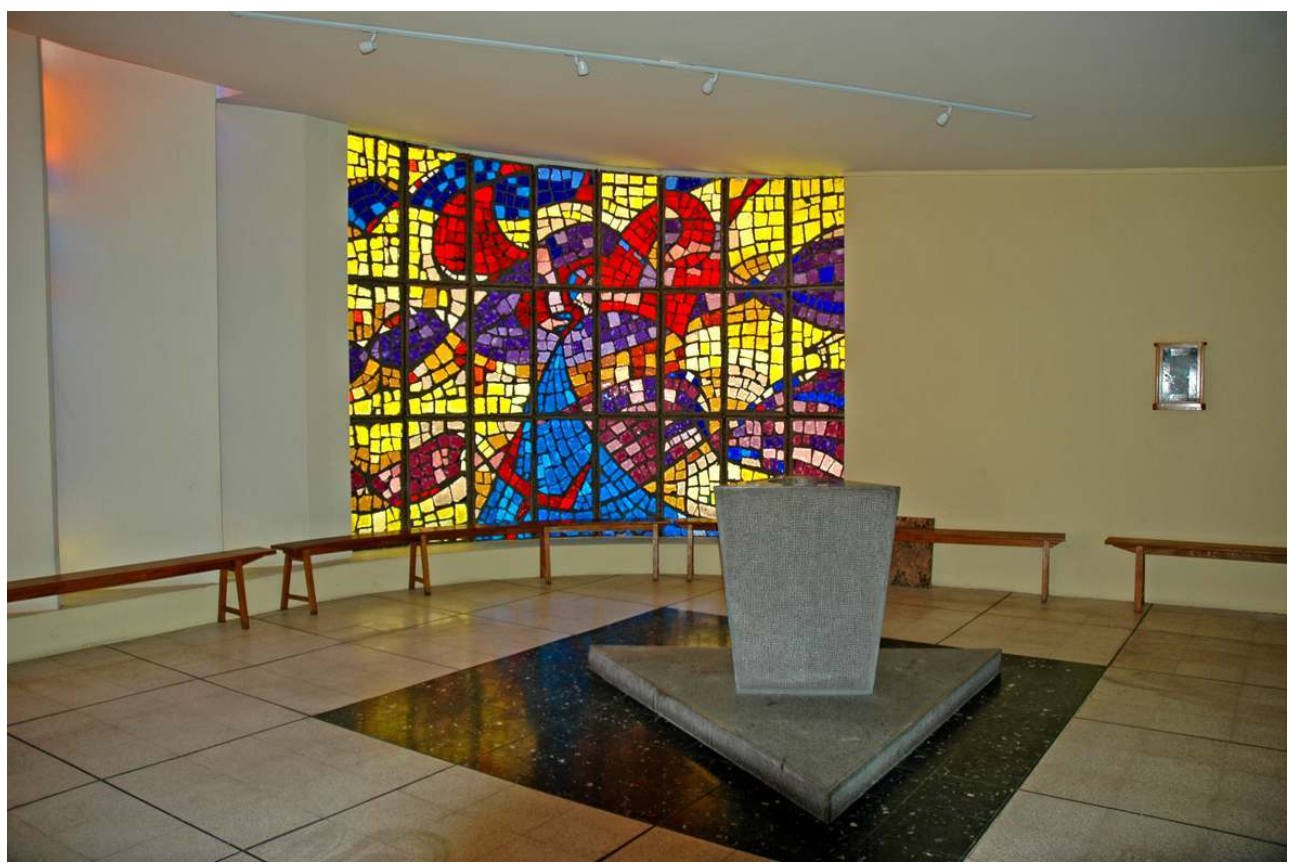

Église Saint-Michel. Les fonts baptismaux, éclairés des vitraux de R.-M. Burlet

Phot. M. Chalabi, 2006. (C) Région Rhône-Alpes, Inventaire général du patrimoine culturel

Saint-Jean-Apôtre ${ }^{115}$, A. Chomel apporte une solution originale : la piscine baptismale ${ }^{116}$ forme, au pied de la flèche-signal, une pièce triangulaire entre les deux entrées de l'église, directement reliée à un bassin situé sous le portique, ouverte sur les entrées par des baies 
arrondies et éclairée par des pavés de verre irrégulièrement disposés en façade (fig. $\mathbf{n}$ - 28). À Saint-Luc ${ }^{117}$, elle occupe le rez-de-chaussée du clocher construit à l'avant de l'église (fig. $\mathbf{n}^{\circ}$ 29). Ailleurs le baptistère est placé dans le chœur (église du Plateau ${ }^{11819}$ ).

Figure 28

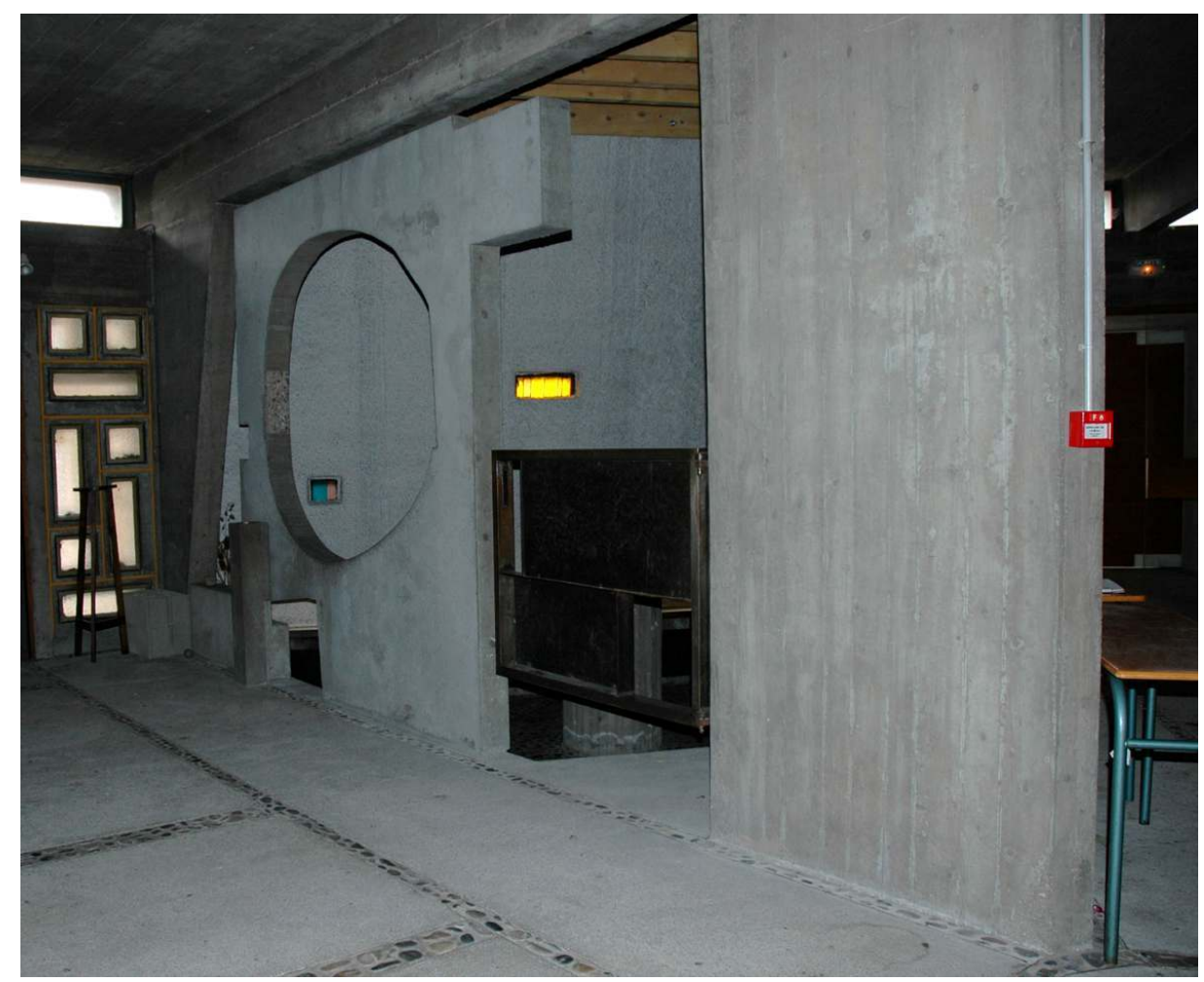

Église Saint-Jean-Apôtre. La piscine baptismale à la base de la flèche-signal Phot. M. Chalabi, 2006. ( ) Région Rhône-Alpes, Inventaire général du patrimoine culturel 


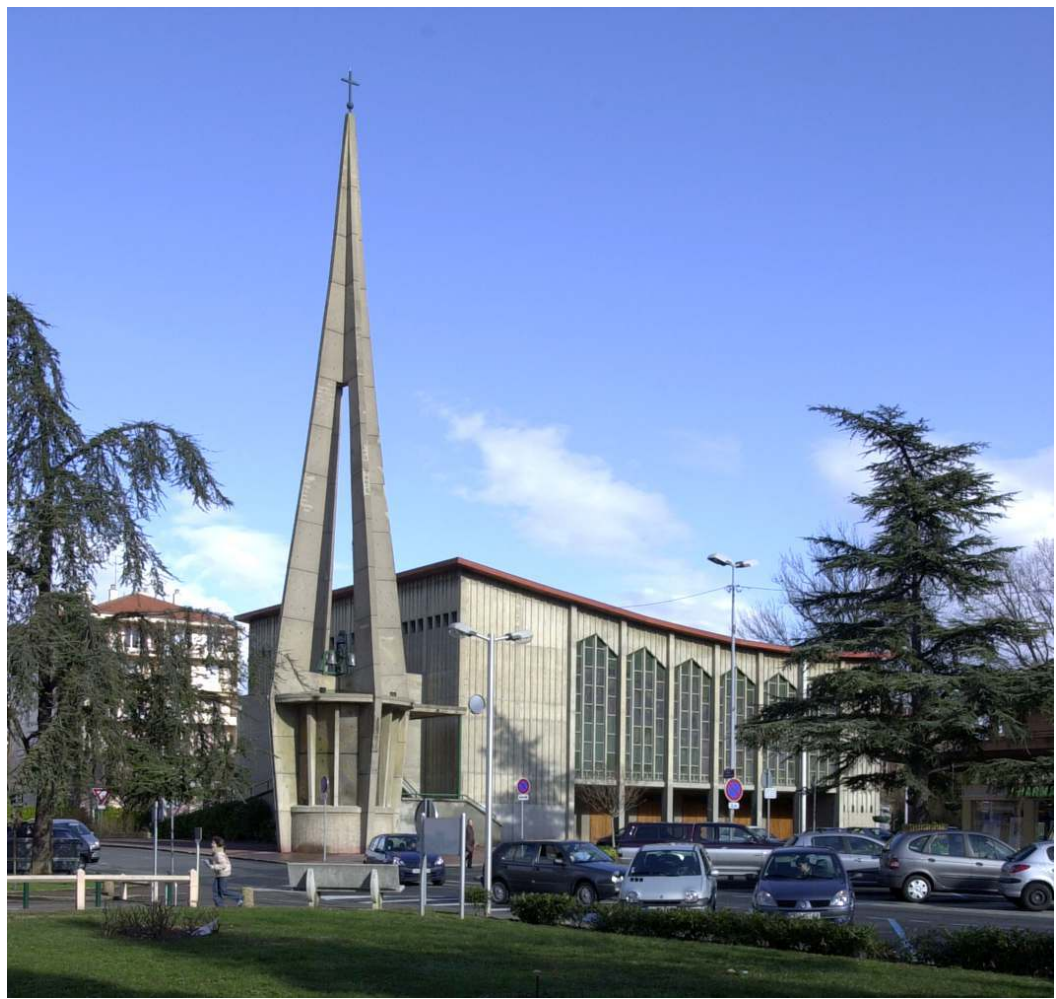

Église Saint-Luc, Sainte-Foy-les-Lyon. La chapelle baptismale à la base du clocher Phot. M. Chalabi, 2006. @ Région Rhône-Alpes, Inventaire général du patrimoine culturel

La lumière est d'une importance majeure dans l'église, et là aussi des solutions diverses ont été apportées. Sainte-Élisabeth ${ }^{120}$ concilie austérité et éclairement par l'utilisation de façades entièrement en parois de verre (voir fig. $\mathbf{n}^{\circ} 22$ ). L'éclairement par des pavés de dalles de verre fait toute la force de l'église Sainte-Marie de la Guillotière ${ }^{121}$ où les vitraux ${ }^{122}$ de Paulin-Besson forment une paroi entière dans la chapelle baptismale et dans le mur sud du sanctuaire ; dans le reste de la nef, dans les chapelles mortuaire et de semaine, ils animent un jeu de claustras le long des façades nord et sud, et forment une bande en haut des murs est et ouest. À Sainte-Anne de Ménival ${ }^{123}$, le vitrail de la chapelle de semaine ${ }^{124}$, du maître-verrier Georges Faure, est un élément fort de décoration de cette église très épurée. À l'Annonciation ${ }^{125126}$, la forte intensité colorimétrique des vitraux de la façade (Maurice Rocher) s'oppose aux grands panneaux monochromes des claustras des bascôtés (Jacques Michel). À Saint-Luc ${ }^{127}$ et Notre-Dame du Point-du-Jour ${ }^{128}$, les concepteurs ont eu recours à de nouveaux matériaux pour avoir de grandes surfaces translucides: parois en résine de polyester réalisées par le moine Pierre Cholewka à Saint-Luc ${ }^{129}$ (fig. $\mathbf{n}$ - 30), (voir fig. $\mathbf{n}^{\circ}$ 15) ; méthacrylate de méthyle recouvert d'une peinture polymérisable, à base d'acétone, à Notre-Dame du Point-du-Jour ${ }^{130}$, procédé et conception des vitraux mis au point par Jean-Marcel Hérault, originaire d'Ardèche et élève d'Albert Gleizes et Louis Barthola. 
Figure 30

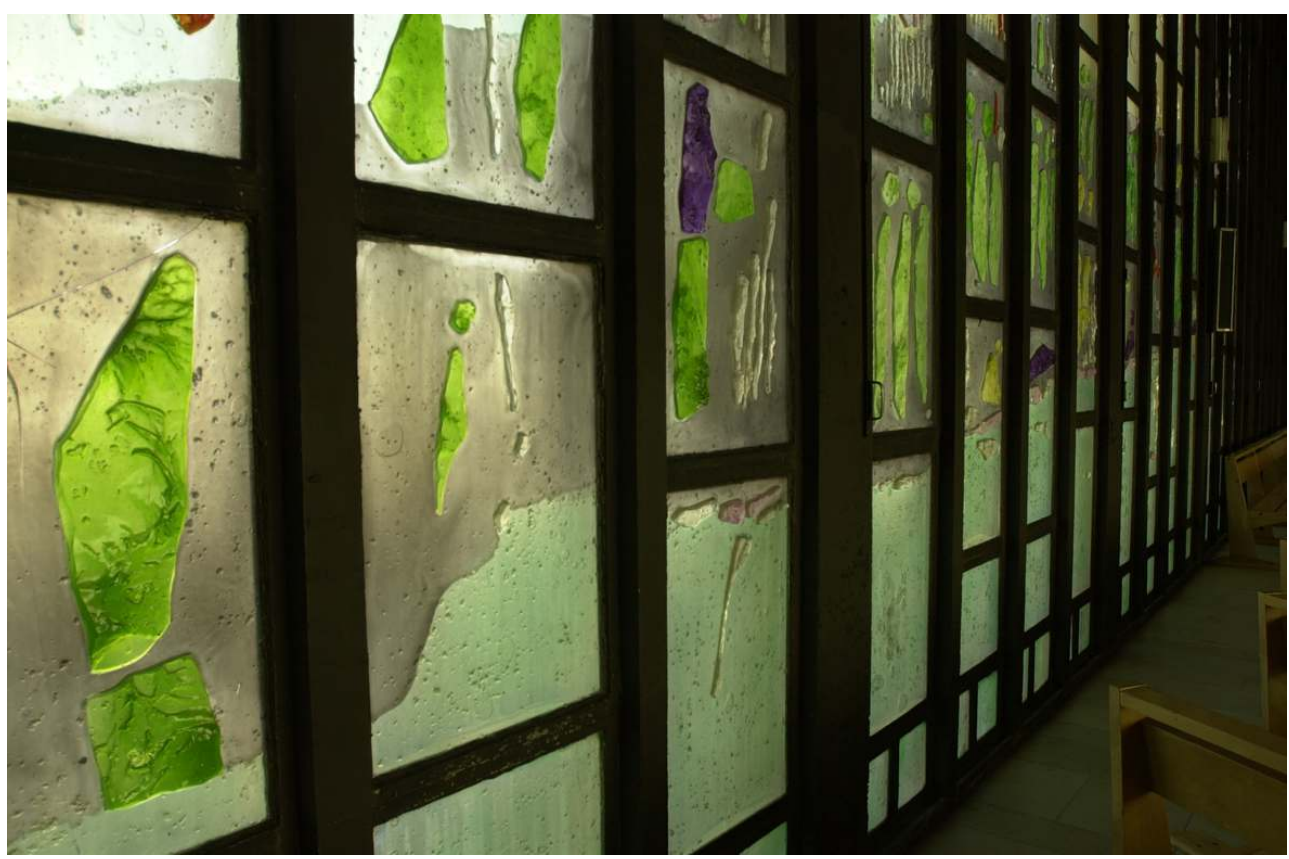

Église Saint-Luc, Sainte-Foy-les-Lyon. Détail des vitraux en résine de polyester

Phot. M. Chalabi, 2006. ( ) Région Rhône-Alpes, Inventaire général du patrimoine culturel jusqu'à 900 places à l'Annonciation de Vaise ${ }^{131132}$ ou à Saint-Michel ${ }^{133}$ (7e arrondissement). Mais tous prévoient une chapelle de semaine ou chapelle d'hiver, parfois complètement séparée de la nef principale (Sainte-Anne de Ménival ${ }^{134}$, Notre-Dame du Point-du-Jour ${ }^{135}$ ), parfois ouverte sur celle-ci (Saint-Michel ${ }^{136}$ ) ou fermée par une cloison mobile (SainteMarie de la Guillotière ${ }^{137}$ ).

L'étude du mobilier pourra faire l'objet d'un autre article. On peut cependant signaler deux grandes options. Les premières églises construites, ou les églises ayant peu de moyens, ont été principalement pourvues de meubles et d'objets provenant d'églises désaffectées ou grâce à des dons des paroisses marraines ou des fidèles. Ces églises mêlent ainsi mobilier et objets anciens et contemporains. C'est le cas par exemple de l'église de la Sainte-Trinité ${ }^{138}$ où l'on trouve des stalles et un siège de célébrant donnés par la paroisse marraine Saint-Bonaventure ${ }^{139}$, des bancs provenant de la chapelle anglicane de La Trinité $^{140}$, quai de Serbie, démolie en 1969, une statue de la Vierge par Joseph-Hugues Fabisch $^{141}$, sauvée d'une démolition passage de l'Hôtel-Dieu en 1959 et donnée à la paroisse par la mairie de Lyon, une armoire $^{142}$ lyonnaise du XVIII $^{\mathrm{e}}$ siècle, vraisemblablement don d'un paroissien. S'y ajoutent les luminaires créés par l'architecte, les fonts baptismaux du ferronnier Jacques Bouget ${ }^{143}$, et le chemin de croix ${ }^{144}$ réalisé à partir de racines de bois fixées sur des ardoises par l'abbé Combet, curé de Fontcouverte en Savoie, œuvre caractéristique du retour à l'art populaire symbole de simplicité.

Dans d'autres églises, l'ensemble du mobilier est conçu en relation directe avec l'architecture. À Saint-Jean-Apôtre ${ }^{145}$, Henri Castella a dessiné un mobilier ${ }^{146}$ en ciment complètement intégré à l'église: confessionnaux ${ }^{147}$, autels, tabernacle, siège de la présidence, crédence, etc. ; son chemin de croix ${ }^{148}$, complètement symbolique, est inséré 
dans le pavement de la nef; la statue ${ }^{149}$ de la Vierge, sculptée par Gabriel Gouttard, est inspirée des Vénus préhistoriques (voir fig. $\mathbf{n}^{\circ} \mathbf{1 6}$ ).

\section{Évolution actuelle}

Églises et centres paroissiaux ont été créés dans un grand élan de volonté pastorale et d'évangélisation des banlieues. Le cardinal Gerlier adresse aux desservants une lettre à lire en chaire le 21 ou le 28 octobre 1963 : «Pouvons-nous accepter que des cités entières manquent de lieux de culte, de salles de catéchisme et de presbytères? Pouvons-nous attendre que les populations de ces cités se soient éloignées de Dieu, en vivant dans un contexte humain privé de lien visible avec l'église et de moyens d'évangélisation? N'est-ce pas une civilisation nouvelle qu'il s'agit de baptiser, au prix d'un effort sans précédent ? "150.

Mais bien vite, il s'est avéré que l'évolution des modes de vie, l'éloignement des populations des pratiques religieuses, le manque de prêtres, rendaient de plus en plus difficile le maintien de tous ces lieux de culte.

Les fermetures et les transformations se sont très rapidement faites. Le cas de la Duchère est encore exemplaire: quatre centres paroissiaux sont ouverts entre 1963 et 1972, l'église du Château est désaffectée en 1981 et convertie en maison de l'enfance, celle de Balmont l'est en 1993 et abrite d'abord un centre de loisirs, puis un cinéma.

Les suppressions de paroisse, les démolitions ou reconversions d'églises se rencontrent dans d'autres quartiers. L'église du Sacré-Cœur (3e), qui avait remplacé en 1934 l'église Sainte-Anne-de-Baraban, est démolie en 1968.

La paroisse des Étroits, partagée entre Lyon 5e et La Mulatière, créée en 1934, est supprimée en 1969, l'église, construite par Louis Mortamet, vendue et transformée en habitation. L'église Saint-François d'Assise de Bron, construite en 1959, est cédée au culte musulman en 1979. Toujours à Bron, la chapelle Sainte-Geneviève, construite en 1967 par Jean-Gabriel Mortamet, est vendue à la commune en 1995 et utilisée comme salle de sports. L'église de Saint-Jean-Apôtre ${ }^{151}$ est affectée au culte maronite en 2003. En 2005, la paroisse Sainte-Marie de la Guillotière ${ }^{152}$ est supprimée ; le diocèse ne peut plus assurer l'entretien de l'église et envisage sa démolition afin de pouvoir revendre le terrain. Le service de l'Inventaire alerte la municipalité et le diocèse sur l'intérêt de cet édifice, un des centres paroissiaux les plus aboutis de la commune, présentant une architecture caractéristique des années 60 , et une église décorée d'un ensemble de vitraux en dalles de verre particulièrement intéressant. L'inspecteur des Monuments historiques émet un avis défavorable à une protection. Le diocèse trouve une solution: l'ensemble est cédé à l'établissement Jeanne-de-Lestonnac qui conserve l'ensemble des bâtiments afin d'y implanter une annexe de son collège. L'aménagement intérieur de l'église prévoit la préservation des vitraux.

67 L'association diocésaine est actuellement propriétaire de 54 lieux de culte sur l'agglomération lyonnaise ; elle s'interroge sur le devenir à plus ou moins long terme de 17 d'entre eux.

68 Mais parallèlement, répondant à l'appel de Mgr Lustiger sur la nécessité de construire de nouvelles églises, l'église Saint-Thomas, à Vaulx-en-Velin, conçue par le cabinet d'architecture Sixt'-In, flanquée d'un clocher bien identifiable, va voir le jour d'ici $2011^{153}$. 

le SRI et l'université, montrent la richesse de ce patrimoine, profondément représentatif dans ses conceptions architecturales et d'aménagement intérieur des tendances nationales. Ils soulignent aussi sa fragilité, et la nécessité de réfléchir à une politique de protection qui viendrait compléter l'enregistrement de la mémoire patrimoniale.

\section{BIBLIOGRAPHIE}

\section{Sources}

A. diocésaines. Archives de l’O.P.D.N. ; Dossiers par églises.

Mazioux, Mgr. Les églises nouvelles dans le diocèse de Lyon. Saint-Étienne : impr. Dumas, 1963.

La Semaine religieuse du diocèse de Lyon, 1955-1967 ; devenue Église de Lyon, 1968-1969.

Revue L'Art sacré, 1948-1965.

\section{Travaux historiques}

Architecture religieuse au $\mathrm{XX}^{\mathrm{e}}$ siècle. Quel patrimoine ? dir. Céline Frémaux. Rennes : Presses universitaires de Rennes, Institut national du patrimoine, 2007.

Bertin, Dominique. Religion moderne, matériaux actuels. L'architecture religieuse de l'aprèsguerre. Monuments historiques, $\mathrm{n}^{\circ}$ 202, mai-juin 1996.

Bertin, Dominique, Reynaud, Jean-François, Reveyron, Nicolas. Guide des églises de Lyon. Lyon : Éditions lyonnaises d'art et d'histoire, 2000, p. 18-20, 25-26, 50.

Candiard, Annabel. Inventaire des églises de Lyon et des communes limitrophes - 1945-1970. Univ. Lumière Lyon 2 : Histoire de l'Art. mém. Maîtrise, 1995.

Capellades, Jean. Guide des églises nouvelles en France. Les éd. du Cerf, 1969. (Les Guides de l'Art sacré).

Debié, Franck, Vérot, Pierre. Urbanisme et art sacré. Une aventure du $\mathrm{XX}^{\mathrm{e}}$ siècle. Paris : Critérion, 1991.

Le diocèse de Lyon, dir. Jacques Gadille. Paris : Beauchesne, 1983. (Histoire des diocèses de France ; 16), p. 297.

Dufieux, Philippe. Architecture et art sacré : Lyon 1905-1958. Univ. Lumière Lyon 2 : histoire de l'art. mém. DEA, 1996.

Dufieux, Philippe. L'architecture religieuse de P. Curtelin. Univ. Lumière Lyon 2 : histoire de l'art. mém. Maîtrise, 1995. 
Gardes, Gilbert. Lyon, l’art et la ville. Paris : éd. du CNRS, 1988, t. 2, p. 166-183.

Gautier-Clere, Alexandra. Les vitraux des églises de Lyon de 1945 à nos jours. Univ. Lumière Lyon 2 : histoire de l'art. mém. Maîtrise, 1998.

Guyon, Véronique. M. Novarina - Éléments pour une étude de ses constructions religieuses. Univ. Lumière Lyon 2 : histoire de l'art. mém. Maîtrise, 1995.

Jacquemin, Louis. Histoire des églises de Lyon. Lyon : Bellier, 1983.

Lehmann, Pierric. Saint-Vincent-de-Paul, Saint-Jean-Apôtre et Sainte-Trinité, trois exemples d'églises nouvelles construites dans le huitième arrondissement de Lyon. Univ. Lumière Lyon 2 : histoire de l'art. mém. master 1, 2008.

Minard Claire. Le rôle de la lumière dans l'architecture religieuse de Pierre Genton. Univ. Lumière Lyon 2 : histoire de l'art. mém. DEA, 1996.

Minard, Claire. Une reconstruction de guerre à Lyon. L'église de l'Annonciation, Vaise : 1953-1957. Univ. Lumière Lyon 2 : histoire de l'art. mém. Maîtrise, 1995.

Saëz, Émilie. Architecture contemporaine et religieuse. Inventaire de cinq églises construites après 1945 à Lyon. Saint-Charles de Serin, Sainte-Élisabeth, Saint-Luc, Sainte-Anne de Ménival, Notre-Dame du Point-du-Jour. Univ. Lumière Lyon 2 : histoire de l'art. mém. mastère 1, 2006.

\section{NOTES}

1. Cet article est un point d'étape d'une étude engagée par le Service de l'Inventaire du patrimoine culturel - Région Rhône-Alpes, en collaboration avec l'université Lyon II (Mme Dominique Bertin) et la Conservation des Monuments historiques, afin de connaître les églises construites au XXe siècle dans l'agglomération lyonnaise et de mener une protection raisonnée de ces édifices. Actuellement aucune de ces églises n'est protégée $\mathrm{MH}$; deux églises seulement ont reçu le label XX $X^{\mathrm{e}}$ : l'Annonciation à Vaise et Notre-Dame du Monde entier à La Duchère. Les premières monographies d'églises ont été réalisées par Émilie Saëz et Pierric Lehmann, étudiants en mastère 1. Les dossiers en ligne sont consultables sous http://sdx.rhonealpes.fr. Dans cet article, nous n'étudierons que Lyon et les communes de la première couronne: Villeurbanne, Caluire-et-Cuire, Collonges-au-Mont-d'Or, Saint-Cyr-au-Mont-d'Or, Saint-Didier-au-Mont-d'Or, Champagne-au-Mont-d'Or, Écully, Tassin-la-Demi-Lune, Francheville, Sainte-Foy-les-Lyon, La Mulatière, Oullins, Pierre-Bénite, Saint-Fons, Vénissieux et Bron.

2. Sources: Grand Lyon.

3. La Semaine religieuse du diocèse de Lyon, 29 mai 1959, p. 312-315 ; 5 juin 1959, p. 322-325.

4. En 1970, le département de la Loire forme un nouveau diocèse, celui de Saint-Étienne.

5. En 1950, René Gagès et Franck Grimal inaugurent la technique dite des "chemins de grues » pour la construction de l'unité de voisinage de Bron-Parilly.

6. A. diocésaines. Rapport général sur le problème des nouveaux lieux de culte dans le diocèse de Lyon, 22 juin 1967.

7. La Semaine religieuse du diocèse de Lyon, 19 octobre 1962, p. 686.

8. A. diocésaines. Notes relatives à l'édification des églises paroisses nouvelles du diocèse de Lyon, 1959.

9. A. diocésaines. Dossiers des églises concernées.

10. Versement en cours dans le dossier électronique : notice IA69005288.

11. Portier, O. L'église de la Trinité selon les dessins de l'Apocalypse. Le Matin, 23 février 1986.

12. A. diocésaines. Dossier de l'église Saint-François d'Assise - Saint-Rambert.

13. La Semaine religieuse du diocèse de Lyon, 21-28 décembre 1956. 
14. La Semaine religieuse du diocèse de Lyon, 3 avril 1959.

15. La Semaine religieuse du diocèse de Lyon, 3 juillet 1959.

16. La Semaine religieuse du diocèse de Lyon, décembre 1960, p. 34.

17. La Semaine religieuse du diocèse de Lyon, décembre 1960, p. 380.

18. La Semaine religieuse du diocèse de Lyon, 3 avril 1959.

19. La Semaine religieuse du diocèse de Lyon, 28 juin 1963, p. 486-492.

20. La Semaine religieuse du diocèse de Lyon, 11 septembre 1964, p. 606-615.

21. La Semaine religieuse du diocèse de Lyon, 21 octobre 1966, p. 698.

22. Versement en cours dans le dossier électronique : notice IA69004104.

23. A. diocésaines. Dossier de l'église Sainte-Trinité.

24. Voir dans la base Mérimée : notice PA00118416.

25. Debié, F., Vérot, P. Urbanisme et art sacré. Une aventure du $\mathrm{XX}^{\mathrm{e}}$ siècle. Paris : Critérion, 1991.

26. Voir dans la base Mérimée : notice PA00117761.

27. La Semaine religieuse du diocèse de Lyon, 27 avril 1956.

28. Lettre de l'évêque aux prêtres du diocèse, 12 juin 1960. Cité par Mazioux, Les églises nouvelles..., 1963, p. 33.

29. Conclusion $d u n^{\circ}$ spécial de Fêtes et Saisons consacré aux églises nouvelles, citée par La Semaine religieuse du diocèse de Lyon, 1963, p. 187.

30. Ces architectes sont évidemment acteurs de l'évolution architecturale et urbanistique de Lyon : voir Marrey, Bernard. Guide Rhône-Alpes de l'architecture du XX $\mathrm{X}^{\mathrm{e}}$ siècle. Paris : Picard, 2004.

31. A. diocésaines. Rapport à l'évêque, 15 février 1960 ; compte rendu de réunion, 21 août 1963. Les archives de la commission d'art sacré n'ont pas encore été exploitées.

32. Winninger, Paul. Construire des églises. Paris : Cerf, 1957.

33. A. diocésaines. Rapport général sur le problème des nouveaux lieux de culte dans le diocèse de Lyon, 22 juin 1967.

34. Versement en cours dans le dossier électronique : notice IA69005288.

35. Versement en cours dans le dossier électronique : notice IA69006521.

36. Voir dans le dossier électronique : notice IA69003091.

37. Versement en cours dans le dossier électronique : notice IA69004104.

38. A. diocésaines. Rapport général sur le problème des nouveaux lieux de culte dans le diocèse de Lyon, 22 juin 1967.

39. Voir dans le dossier électronique : notice IA69002102.

40. Versement en cours dans le dossier électronique : notice IA004121.

41. Voir dans le dossier électronique : notice IA69000724.

42. Voir dans la base Mérimée : notice EA69141256.

43. Couronnement de ferronnerie par Stahly et Jacques Bouget, cloches par les fils de G. Paccard, horloge de Mammias.

44. Voir dans le dossier électronique : IA69003074.

45. Versement en cours dans le dossier électronique : notice IA69005288.

46. Versement en cours dans le dossier électronique : notice IM69000896.

47. La Semaine religieuse du diocèse de Lyon, 11 septembre 1964, compte rendu des cinq rencontres entre l'évêque et les archiprêtres.

48. Voir dans le dossier électronique : notice IA69003075.

49. Versement en cours dans le dossier électronique : notice IA69004168.

50. Versement en cours dans le dossier électronique : notice IA69004104.

51. En 1959, les rédacteurs de la revue l'Art sacré écrivaient "un sort malveillant semble s'attacher aux projets d'église de Pierre Genton. Voilà près de dix ans qu'il poursuit des recherches de valeur et souvent neuves dans le domaine de l'architecture religieuse, mais il n'a pas encore construit une seule 
église... La qualité de ses œuvres est probablement trop raffinée pour être perçue par un jury ébloui par le grandiose et le tape-à-l'œil » L'Art sacré, n³-4, novembre-décembre 1958, p. 29. Après l'église de la Trinité, P. Genton se voit confier les chantiers des églises Notre-Dame de Lourdes (Bron Parilly), de Balmont (9e), Notre-Dame de l'Espérance (Villeurbanne), Notre-Dame du Bon Conseil (Oullins)...

52. Versement en cours dans le dossier électronique : notice IM69001147.

53. A. paroissiales Sainte-Trinité.

54. Voir dans le dossier électronique : notice IA69004080.

55. La Semaine religieuse du diocèse de Lyon, 5 janvier 1962, p. 83. Les trois premiers prix sont attribués à Paul Curtelin, Pierre Genton et Alain Chomel et Beaupère. Les projets donnent lieu à une exposition dans le hall de l'office départemental du bâtiment et des travaux publics du 5 au 21 janvier 1962.

56. A. privées P. Curtelin.

57. Il faut noter cependant que la moitié des églises construites conservent un plan rectangulaire.

58. Voir dans le dossier électronique : notice IA69004080.

59. Voir dans le dossier électronique : notice IA69004079.

60. L'Art sacré, no 7-8, mars-avril 1961, p. 24-31.

61. Voir dans le dossier électronique : notice IA69002130.

62. Voir dans la base Mérimée : notice EA69141255.

63. L'Art sacré, nº 5-6, janvier-février 1965, p. 19.

64. L'Art sacré, n 5-6, janvier-février 1965, p. 19 ss.

65. Capelladès, Jean. Guide des églises nouvelles en France, 1969.

66. Voir dans le dossier électronique : notice IA69004080.

67. Versement en cours dans le dossier électronique : notice IA69005288.

68. Versement en cours dans le dossier électronique : notice IM69000896.

69. Versement en cours dans le dossier électronique : notices IA69006521, IM69001032.

70. Cette église remplace une église détruite par les bombardements et, à ce titre, a été financée à $50 \%$ par l'État.

71. Voir dans le dossier électronique : notices IA69003091 et IM69001103.

72. Voir dans le dossier électronique: notices IA69004079; IM69002507; IM69002505; IM69002506.

73. Versement en cours dans le dossier électronique : notice IA69004168.

74. Voir dans la base Mérimée : notice IA69000724.

75. Voir dans la base Mérimée : notice EA69141256.

76. Versement en cours dans le dossier électronique : notice IA69004104.

77. Voir dans le dossier électronique : notice IA69004080.

78. Voir dans le dossier électronique : notice IA69000724.

79. Voir dans la base Mérimée : notice EA69141256.

80. Voir dans le dossier électronique : notice IA69003074.

81. Voir dans le dossier électronique : notice IA69003091.

82. Voir dans le dossier électronique : notice IA69003075.

83. Versement en cours dans le dossier électronique : notice IA69005288.

84. Versement en cours dans le dossier électronique : notice IA69004168.

85. Voir dans le dossier électronique : notice IA69003091.

86. Versement en cours dans le dossier électronique : notice IA69004104.

87. Voir dans le dossier électronique : notice IA69004079.

88. Voir dans le dossier électronique : notice IA69003074.

89. Versement en cours dans le dossier électronique : notice IA69005288.

90. Voir dans le dossier électronique : notice IA69004080. 
91. Versement en cours dans le dossier électronique : notice IA69006521.

92. Voir dans le dossier électronique : notice IA69002130.

93. Voir dans la base Mérimée : notice EA69141256.

94. Gadille, Lyon, p. 296-297.

95. Voir dans le dossier électronique : notices IA69003091; IM69001103.

96. Voir dans le dossier électronique : notices IA69003075 ; IM69001101.

97. Voir dans le dossier électronique : notices IA69004079; IM69002510.

98. Voir dans le dossier électronique : notices IA69004080 ; IM69002511.

99. Versement en cours dans le dossier électronique : notices IA69006521, IM69001032.

100. Versement en cours dans le dossier électronique : notices IA69004104, IM69001146.

101. Voir dans le dossier électronique : notices IA69002130 ; IM69001078.

102. Voir dans la base Mérimée : notice EA69141256.

103. A. privées P. Curtelin. Allocution prononcée par l'architecte lors de la consécration de l'église, 11 mai 1968.

104. Voir dans le dossier électronique : notice IA69004079.

105. A. diocésaines. Notes relatives à l'édification des églises paroisses nouvelles du diocèse de Lyon, 1959.

106. En 1963, les rédacteurs de la revue L'Art sacré estiment que la nouvelle tendance préconisant de situer le baptistère dans le chœur semble encore trop «inspirée du protestantisme » $\left(\mathrm{n}^{\circ} 5-6\right.$, janvier-février 1963, p.11); en 1969 cette solution est préconisée par le Guide des églises nouvelles, p. 43.

107. Voir dans le dossier électronique : notice IA69000724.

108. Voir dans la base Mérimée : notice EA69141256.

109. Voir dans le dossier électronique : notice IA69003074.

110. Versement en cours dans le dossier électronique : notice IA69005288.

111. Versement en cours dans le dossier électronique : notice IA69004104.

112. Versement en cours dans le dossier électronique : notice IM69001149.

113. Voir dans le dossier électronique : notice IA69003075.

114. Voir dans le dossier électronique : notice IA69003091.

115. Versement en cours dans le dossier électronique : notice IA69004168.

116. Versement en cours dans le dossier électronique : notice IM69001141.

117. Versement en cours dans le dossier électronique : notice IA69006521.

118. Voir dans le dossier électronique : notice IA69002130.

119. Voir dans la base Mérimée : notice EA69141255.

120. Voir dans le dossier électronique : notice IA69003075.

121. Versement en cours dans le dossier électronique : notice IA69005288.

122. Versement en cours dans le dossier électronique : notice IM69000896.

123. Voir dans le dossier électronique : notice IA69004080.

124. Voir dans le dossier électronique : notice IM69002509.

125. Voir dans le dossier électronique : notice IA69000724.

126. Voir dans la base Mérimée : notice EA69141256.

127. Versement en cours dans le dossier électronique : notice IA69006521.

128. Voir dans le dossier électronique : notice IA69004079.

129. Versement en cours dans le dossier électronique : notice IM69001032.

130. Voir dans le dossier électronique : notices IM69002507 ; IM69002505 ; IM69002506.

131. Voir dans le dossier électronique : notice IA69000724.

132. Voir dans la base Mérimée : notice EA69141256.

133. Voir dans le dossier électronique : notice IA69003091.

134. Voir dans le dossier électronique : notice IA69004080.

135. Voir dans le dossier électronique : notice IA69004079. 
136. Voir dans le dossier électronique : notice IA69003091.

137. Versement en cours dans le dossier électronique : notice IA69005288.

138. Versement en cours dans le dossier électronique : notice IA69004104.

139. Voir dans la base Mérimée : notice PA00117794.

140. Voir dans le dossier électronique : notice IA69002114.

141. Versement en cours dans le dossier électronique : notice IM69001148.

142. Versement en cours dans le dossier électronique : notice IM69001152.

143. Versement en cours dans le dossier électronique : notice IM69001149.

144. Versement en cours dans le dossier électronique : notice IM69001150.

145. Versement en cours dans le dossier électronique : notice IA69004168.

146. Versement en cours dans le dossier électronique : notices IM69001135, IM6900117.

147. Le diocèse recommande de concevoir les confessionnaux « comme des alvéoles composées avec le gros cuvre, plutôt que comme des meubles". A. diocésaines. Note relative à l'édification des églises, 1959.

148. Versement en cours dans le dossier électronique : notice IM69001140.

149. Versement en cours dans le dossier électronique : notice IM69001136.

150. La Semaine religieuse du diocèse de Lyon, octobre 1963.

151. Versement en cours dans le dossier électronique : notice IA69004168.

152. Versement en cours dans le dossier électronique : notice IA69005288.

153. Dans la même commune sont également construits un temple et une mosquée.

\section{RÉSUMÉS}

La population du diocèse de Lyon augmente de 400000 habitants entre 1900 et 1959, et la population urbaine représente désormais $62 \%$ de la population totale du diocèse. Pour répondre à cette évolution, l'archevêque de Lyon crée l'O.D.P.N. (Office diocésain des paroisses nouvelles). La construction de 120 centres paroissiaux est prévue pour 1964. Les premières constructions sont assez classiques (avec notamment des clochers monumentaux), et seul l'usage du béton brut marque une ouverture au modernisme. Après 1960, les curés bâtisseurs font appel à des architectes novateurs qui inventent des formes nouvelles, mais qui ne s'imposent pas dans le paysage urbain. Les dispositions intérieures relèvent des tendances modernistes et des prescriptions du concile Vatican 2. Après 1973, il n'y a pas de nouvelles constructions d'églises dans la ville, et même plusieurs fermetures sont actées ou envisagées. Cette situation attire l'attention sur la fragilité du patrimoine religieux contemporain de Lyon, qui est à la fois original et représentatif des tendances nationales.

The population of the diocese of Lyon grew by 400,000 between 1900 and 1959 and $62 \%$ of this total population were now city-dwellers. In order to respond to this evolution, the archbishop of Lyon created the O.D.P.N. (Office diocésain des paroisses nouvelles, Diocesan Office of New Parishes). It planned the creation of 120 new parish centres by 1964 . The first buildings were fairly classical, often with monumental bell towers. Only the use of untreated reinforced concrete suggested a sensitivity to the trends of modern architecture. After 1960, however, parish priests began to commission buildings from innovative architects who began to design new forms, but which did not really mark the landscape. Inside, the design reflected the modernist tendencies and prescriptions of the Vatican 2 Council. After 1973, there were no new churches built in the 
city, and some existing churches were even closed down. This situation draws attention to the fragility of the contemporary religious heritage of Lyon, which has its own originality but which is broadly representative of national tendencies.

\section{INDEX}

Mots-clés : établissement Jeanne-de-Lestonnac, Germaine Richier, Joseph-Hugues Fabisch, Gabriel Gouttard, Paulin, Besson, Georges Faure, Maurice Rocher, Jacques Michel, Jean-Marcel Hérault, Albert Gleizes, Louis Barthola, Jacques Bouget, percement du tunnel de la Croix-Rousse, Charles Tolot, Le Corbusier, Pierre Genton, Paul Curtelin, Jean-Gabriel Mortamet, Joseph Bacconnier, René Gagès, Marc Bissuel, François-Régis Cottin, Paul-Erasme Koch, Louis Mortamet, Franck Grimal, Pierre Bourdeix, Daniel Genevois, Roger Mermet, Marcel Sabattier, Alain Chomel, Maurice Novarina, Emile Agniel, Henri Castella, Sainte-Marie de la Guillotière à Lyon, SaintFrançois d'Assise de Lyon, Saint-Martin d'Ainay de Lyon, Sainte-Trinité de Lyon, couvent des dominicains de la Tourette à Eveux, Saint-Luc de Sainte-Foy-les-Lyon, Saint-Michel de Lyon, églises de La Duchère, centre paroissial des Minguettes à Vénissieux, Notre-Dame de Saint-Alban de Lyon, Saint-Pierre de Vaise à Lyon, Saint-Vincent-de-Paul de Lyon, église de l'Annonciation de Vaise à Lyon, église Saint-Charles de Serin à Lyon, Christ-Roi de Bron-Parilly, Saint-François d'Assise de Bron, Sainte-Elisabeth de Lyon, Saint-Jean Apôtre de Lyon, centre paroissial de Ménival à Lyon, Sainte-Anne de Ménival à Lyon, Notre-Dame-de-Lourdes de Bron, Notre-Dame du Point-du-Jour de Lyon, Notre-Dame du Roule de La Mulatière, église du Plateau à Lyon, église de la Duchère à Lyon, église de Balmont à Lyon, église du Château à Lyon, église de la Sauvegarde à Lyon, Notre-Dame du Monde entier de Lyon, Saint-Michel de Berthelot de Lyon, Notre-Dame d'Espérance de Villeurbanne, Sainte-Thérèse de la Plaine de Sainte-Foy-les-Lyon, Saint-Julien de Cusset de Villeurbanne, Saint-Bonaventure de Lyon, chapelle de La Trinité de Lyon, église du Sacré-Cœur de Lyon, Sainte-Anne-de-Baraban de Lyon, chapelle Sainte-Geneviève de Bron, SaintThomas de Vaulx-en-Velin, églises paroissiales XXe siècle, églises paroissiales contemporaines, églises paroissiales Lyon, églises paroissiales XXe siècle Lyon, églises paroissiales contemporaines Lyon, construction d'églises, église-monument, concile Vatican II, L'Art sacré, Mgr Dupuy, Mgr Mazioux, abbé de Pazanan, père Winninger, père Laurent Rémilleux, père Régamey, Mgr G. de Vaumas, cardinal Lercaro, cardinal Gerlier, moine Pierre Cholewka, abbé Combet, Mgr Lustiger, paroisse Notre-Dame de Lourdes à Lyon, paroisse du Christ-Roi à Bron-Parilly, paroisse SansSouci à Lyon, paroisse des Etroits, Commission d'art sacré, Office diocésain des paroisses nouvelles, Institut de sociologie religieuse des facultés catholiques, Comité national de construction d'églises, Le Christ dans la banlieue, CEuvre du Christ dans la banlieue

Keywords : Jeanne-de-Lestonnac establishment, the Example of Lyon, 20th-century parish churches, Contemporary parish churches, Lyon parish churches, 20th-century parish churches in Lyon, Church building, Church-monuments, Vatican 2 Council, Father Winninger, Father Laurent Rémilleux, Father Régamay, Monk Pierre Cholewka, Commission of sacred art, Christ in the suburbs, Euvre of Christ in the suburbs, Parish of Christ-Roi at Bron-Parilly, Parish of NotreDame de Lourdes at Lyon, Sans-Souci parish in Lyon, Parish of Etroits, Dominican convent of La Tourette at Eveux, Churches of La Duchère, Parish centre of the Minguettes at Vénissieux, Church of the annunciation at Vaise, Lyon, Church of Saint-Charles de Serin at Lyon, Ménival parish centre at Lyon, Sainte-Anne de Ménival at Lyon, Notre-Dame-de-Lourdes at Lyon, Plateau church at Lyon, Church of La Duchère at Lyon, Balmont church at Lyon, Church of the Château at Lyon, Church of la Sauvegarde at Lyon, Chapel of the Trinité at Lyon, Church of the Sacré-Cœur at Lyon, Sainte-Anne de Barbaran de Lyon, Sainte-Geneviève chapel at Bron, Cutting of the tunnel beneath the Croix-Rousse, Sacred art 


\section{AUTEUR}

\section{MARYANNICK CHALABI}

Conservateur en chef du patrimoine, Inventaire du patrimoine culturel, région Rhône-Alpes.

MCHALABI@rhonealpes.fr 